\title{
Anticipated Impact of Hand-Hold Position on the Electromagnetic Interaction of Different Antenna Types/Positions and a Human in Cellular Communications
}

\author{
Salah I. Al-Mously ${ }^{1,2}$ and Marai M. Abousetta' \\ ${ }^{1}$ Department of Electrical and Electronics Engineering, School of Applied Sciences and Engineering, Academy of Graduate Studies, \\ P.O. Box 79031, Janzoor, Tripoli, Libya \\ ${ }^{2}$ Microwave and Radar Engineering Department, The Higher Institute of Electronics, P.O. Box 38645, Beni-Walid, Libya
}

Correspondence should be addressed to Salah I. Al-Mously, salah.mously@ieee.org

Received 26 August 2008; Accepted 28 September 2008

Recommended by J. Nadobny

\begin{abstract}
This paper is intended to investigate intensely the impact of multipossible hand-hold positions on the electromagnetic (EM) interaction of handset antennas and a human by using a finite-difference time-domain (FDTD) method. Candy-bar handsets with different external and internal antenna positions operating in the GSM900, GSM1800/DCS, and UMTS/IMT-2000 bands are hereby simulated with configuration of the most parts in order to achieve the commercially available handset model design. Homogeneous and heterogeneous phantoms both are used to simulate the human head, whereas, a semirealistic model with three different tissues is designed to simulate a human hand holding a set. Both of the antenna performance including the total isotropic sensitivity (TIS) and the specific absorption rate (SAR) in tissues are examined for the different suggested applicable cases, where various positions of antenna, handset and hand are considered in simulations. This simulation study determines that both of the antenna performance and the SAR in tissues significantly alter owing to the positioning of the handset against user's head at different hand levels; where a maximum alteration is observed due to the exposure of handset with internal antenna, as compared with the handset having external antenna.
\end{abstract}

Copyright (c) 2008 S. I. Al-Mously and M. M. Abousetta. This is an open access article distributed under the Creative Commons Attribution License, which permits unrestricted use, distribution, and reproduction in any medium, provided the original work is properly cited.

\section{INTRODUCTION}

The possible health hazard of cellular communication handsets due to their electromagnetic (EM) interaction with human and the means of reducing the impact of this interaction have appeared as a public concern. It is noticeable that while using cellular handset in close proximity to head, many factors may affect on the EM interaction, among them is the hand-hold position.

Measuring the specific absorption rate (SAR) in human head exposed to the handset antenna radiation, most standards (IEEE-1528, EN 50360/1, IEC 62209, ARIB STDT56, FCC, ACA) [1-7] ignore considering the use of hand model due to the various possible hand-hold positions and the worst-case SAR value is obtained without the use of a hand model. However, the hand-hold has a considerable impact on the handset antenna performance which can be altered according to the antenna type/position and handhold position. Hence, it is highly significant to anticipate the EM interaction of handset antennas and a human head taking into account the different possible hand-hold positions.

Although over the last fifteen years many authors have investigated the interaction between the EM field radiated by the cellular hand-held and human head [8-23], nothing has been published yet about the hand effect on the EM interaction after examining both antenna performance and the SAR in tissues, by taking into consideration the effects of different operating frequencies, different antenna types, and different positions of the hand, antenna, and handset against head.

In [8-12], user's hand was simulated by a simple block model, where in [8], the model consists of one tissue (muscle), whereas in [9-12], the models consisted of two 
tissues (bone and muscle). In [13, 14], a hand with typical handset holding model was simulated with one tissue approximating the average hand tissues relative permittivity. In [15], user's hand was simulated by a 3D anatomical model with eleven tissues, based on its real geometry acquired by an MR scan. A homogeneous 3D model was used in [16] to simulate the user's hand, whereas a realistic model with two tissues (bone and muscle) was used in [17]. A simplified model of a hand grasping a cellular phone was presented in [18], where the hand model can be digitally moved while grasping the handset with external antenna. A thin rubber glove filled with a muscle simulating liquid was used in [14, 15] to conduct the experimental measurement of the hand impact beside the simulation, whereas in [19], PVC tubes filled with a lossy liquid at the cheek left position was used to conduct the measurement at both 900 and $1800 \mathrm{MHz}$. In [20-22], a semirealistic model with three tissues (bone, muscle, and skin) was designed and used to simulate the user's hand, whereas in [23], a realistic model of three tissues was generated and used.

Specifically in $[12-14,16,17,22,23]$, the effect of hand-hold positions was considered in evaluating the EM interaction and was observed as follows.

(1) In [12], two different block models of the hand holding the handset at 900 and $1800 \mathrm{MHz}$ were examined. A simple model of shorted-patch antenna in different orientations over a metal plate (chassis) with $3.6 \mathrm{~mm}$ thickness all were used to simulate the handset. The EM interaction between MRI-based head model with six tissues and the handset were investigated for different chassis lengths. Both the antenna specifications and SAR in tissues were computed due to sliding the hand on the handset at different positions. A single handset position with respect to head was considered. Only the patch antenna was examined, where the different possible antenna positions were ignored.

(2) In [13], both homogeneous and heterogeneous (seven tissues) head models are involved in computing the maximum local SAR in tissues at 900 and $1500 \mathrm{MHz}$. A typical hand model with one tissue sliding on a handset was used, where the handset was modeled by a simple metal box with a monopole and dipole antenna. The maximum local SAR in head was calculated due to different handhold positions and different distances between handset and head. The internal antenna was not examined and the different possible antenna positions on the handset were not considered. The antenna performance due to the hand-hold alteration was not presented.

(3) In [14], two different right-hand-hold positions were considered with two different handset models (one with a right-side monopole and the other with a rectangular patch antenna) against head at cheek position and operating at $1747 \mathrm{MHz}$. Only the antenna performance was evaluated for different antenna orientations, where both experimental and numerical techniques have been conducted. A fiberglass torso phantom of brain/muscle simulating liquid and a thin rubber glove filled with the same liquid were used in measurements, whereas a homogeneous torso plus hand phantom was used in simulations. The different possible antenna positions were not examined in that study.
(4) In [16], three different right-hand-hold positions were considered using a clam-shell phone with a leftside external antenna. Based on the phone type, a cheek position was considered. The simulation was conducted at $1880 \mathrm{MHz}$, where only the antenna performance of the handset against specific anthropomorphic mannequin (SAM) was examined.

(5) In [17], eight right-hand-hold positions sliding on the handset with internal antenna were considered. Only the antenna performance was evaluated at 925 and $1795 \mathrm{MHz}$ with no human-head involvement in computation.

(6) In [22], two applicable extremes of hand holding for a candy-bar handset with external antenna close to head at cheek and tilt positions and operating at $900 \mathrm{MHz}$ were considered. That work did not take into consideration the EM interaction of, firstly, the internal-type antenna, secondly, the possible antenna positions, thirdly, the possible different operating frequencies, and fourthly, the effect of tissues inhomogeneity using an MRI-based head model.

(7) In [23], the performance of a realistic commercial quad-band clamshell-type handset with different external antennas was predicted under various usage patterns. The EM interaction of handset and SAM phantom was computed and measured at $1880 \mathrm{MHz}$, where three different hand-hold positions were examined. The values of SAR in tissues due to the considered different usage patterns were not presented and the effects of head-tissues inhomogeneity as well as the different possible antenna types/positions were ignored.

In this research, a semirealistic right-hand model with three tissues [20-22] is designed to determine the impact of the hand-hold position on the EM interaction between handset antennas and human. Heterogeneous anatomically correct model of twenty five different tissues as well as homogeneous SAM phantom are used to simulate the user's head.

In view of the fact that the external antenna position on a handset has a considerable impact on the EM interaction [20], twelve single-band handset models having different antenna types/positions are designed and simulated to find out the available commercial models design. The earlier six models are with external antennas positioned on the left and right side and operating at 900, 1800, and $2025 \mathrm{MHz}$, whereas the later six models are with internal antennas positioned at top and bottom of the handset and operating at 900,1800 , and $2025 \mathrm{MHz}$.

The prediction of the EM interaction is based on evaluating the handset antenna performance including the total isotropic sensitivity (TIS) as well as the SAR and power absorbed in tissues. Both cheek and tilt positions of the handset against head are examined in compliance with the IEEE-standard 1528 [1].

All simulations are achieved at 900, 1800, and 2025 $\mathrm{MHz}$, which represent the GSM-family standards including E-GSM900 (880-960 MHz), GSM1800/DCS (1710-1880 $\mathrm{MHz}$ ), and UMTS/IMT-2000 (1885-2200 MHz), respectively. For the later, the frequency of $2025 \mathrm{MHz}$ represents the upper edge of the transmitting band of the IMT-2000 (1885$2025 \mathrm{MHz}$ ) also within the range of UMTS band. 

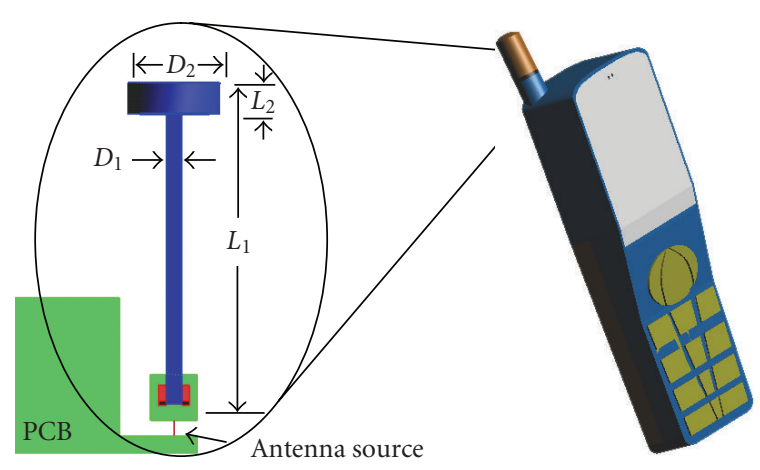

$$
\begin{gathered}
900 \mathrm{MHz} \\
L_{1}=31 \mathrm{~mm} \\
L_{2}=2 \mathrm{~mm} \\
D_{1}=1 \mathrm{~mm} \\
D_{2}=6 \mathrm{~mm}
\end{gathered}
$$

$$
\begin{gathered}
1800 \mathrm{MHz} \\
L_{1}=25 \mathrm{~mm} \\
L_{2}=2 \mathrm{~mm} \\
D_{1}=1 \mathrm{~mm} \\
D_{2}=6 \mathrm{~mm}
\end{gathered}
$$

$$
\begin{aligned}
& 2025 \mathrm{MHz} \\
& L_{1}=20.5 \mathrm{~mm} \\
& L_{2}=2 \mathrm{~mm} \\
& D_{1}=1 \mathrm{~mm} \\
& D_{2}=6 \mathrm{~mm}
\end{aligned}
$$

FIgURE 1: The SEMCAD X representation of the handset with external antenna (model-A1) showing the numerical antenna structure and its dimensions at 900, 1800, and $2025 \mathrm{MHz}$.

\section{FDTD MODELING}

The finite-difference time-domain (FDTD) method proposed by Yee in 1966 [24] is a direct solution of Maxwell's curl equations in the time domain:

$$
\begin{aligned}
& \nabla \times \mathbf{H}=\frac{\partial}{\partial t} \varepsilon \mathbf{E}+\sigma_{E} \mathbf{E}, \\
& \nabla \times \mathbf{E}=-\frac{\partial}{\partial t} \mu \mathbf{H}-\sigma_{H} \mathbf{H},
\end{aligned}
$$

where $\varepsilon$ and $\mu$ are the electric and magnetic properties of the material, respectively; $\sigma_{E}$ and $\sigma_{H}$ are the electric and magnetic conductivity, respectively; and the electric (E) and magnetic $(\mathbf{H})$ field components are positioned as [25]

$$
\mathbf{E}=\left(\begin{array}{c}
E_{x} \\
E_{y} \\
E_{z}
\end{array}\right), \quad \mathbf{H}=\left(\begin{array}{c}
H_{x} \\
H_{y} \\
H_{z}
\end{array}\right) .
$$

Maxwell's curl equations are discretized using a 2nd-order finite-difference approximation in both space and time in an equidistantly spaced mesh, where $\mathbf{E}$ and $\mathbf{H}$ are calculated at alternating discrete points in time using a leap-frog algorithm [24, 25]. Although FDTD technique has some limitations [26], its robustness, its suitability for handling complex problems composed of any number of subvolumes and its general independence of material compositions make it more popular than other techniques and the most applied in EM solver platforms. SEMCAD X (ver. 12.4 JUNGFAU) simulation platform [27] is selected for simulating these work cases due to its handling, functionality, and features for highly detailed CAD models as well as efficient FDTD solver for simulating advanced applications. SEMCAD X is a 3D full wave simulation environment based on the FDTD method.
TABLE 1: The main dielectric parts of the handset CAD models and the corresponding material parameters.

\begin{tabular}{lcc}
\hline Part & $\varepsilon_{r}$ & $\sigma(\mathrm{S} / \mathrm{m})$ \\
\hline Antenna cover and bushing & 2.5 & 0.003 \\
PCB dielectric & 4.5 & 0.07 \\
LCD glass & 4.5 & 0.01 \\
LCD dielectric & 3.0 & 0.01 \\
Housing and covers & 3.5 & 0.02 \\
Keypad/buttons & 3.5 & 0.02 \\
Battery case & 3.5 & 0.02 \\
\hline
\end{tabular}

\subsection{Handset model with external antenna}

For the handset with external antenna, a candy-bar handset operating at $900 \mathrm{MHz}$ [22] is adopted and redesigned to produce six different models with left- and right-side external-antenna operating at 900, 1800, and $2025 \mathrm{MHz}$. The handset with the left-side antenna will be referred later as model-A1, whereas the handset with the right-side antenna will be referred as model-A2. The maximum dimensions of the handset with external antenna (excluding the antenna height) are $104 \mathrm{~mm} \times 43 \mathrm{~mm} \times 16.5 \mathrm{~mm}$ (length $\times$ width $\times$ thickness), whereas the multilayer PCB dimensions are $97 \mathrm{~mm} \times 37 \mathrm{~mm} \times 1 \mathrm{~mm}$.

The considered electromechanical parts of the proposed handset models with external and internal antennas are antenna, external antenna cover, PCB, shields, LCD and its holder, housing parts, keypad and buttons, battery and battery contacts, and connectors. Table 1 shows the dielectric material parameters used for simulations $[22,23,26]$.

A short-whip antenna top-loaded with a small cylinder $[21,22,28]$ is suggested. A matching of $15.25 \mathrm{nH}$ lumped element is needed at $900 \mathrm{MHz}$ [22], whereas at 1800 and $2025 \mathrm{MHz}$, the antenna is well tuned and no matching is considered. The antenna has been tilted back by $\left(8^{\circ}\right)$ to reduce the EM interaction with head. Figure 1 shows the SEMCAD X representation of model-A1 with the antenna configuration and its dimensions at the adopted frequencies, that is, 900,1800 , and $2025 \mathrm{MHz}$.

\subsection{Handset model with internal antenna}

Many techniques were suggested to make the microstrip patch antenna (MPA) suitable in size for the mobile communication terminals. One of the effective ways to reduce the patch size of the microstrip antenna is to introduce a shorting pin at the edge of the patch [29]. An overview and a survey on the compact patch antenna including the antennas with shorting pin are detailed in [30]. The performance of the probe-fed single and stacked shorted-patch antennas due to the EM interaction with the human were investigated in $[11,12]$, where the possible different antenna positions were not examined.

In this work, a semirealistic handset model using a singleband probe-fed rectangular patch antenna with shorting plate at the edge is designed. Six different handset models are simulated with top and bottom-mounted patch antennas 


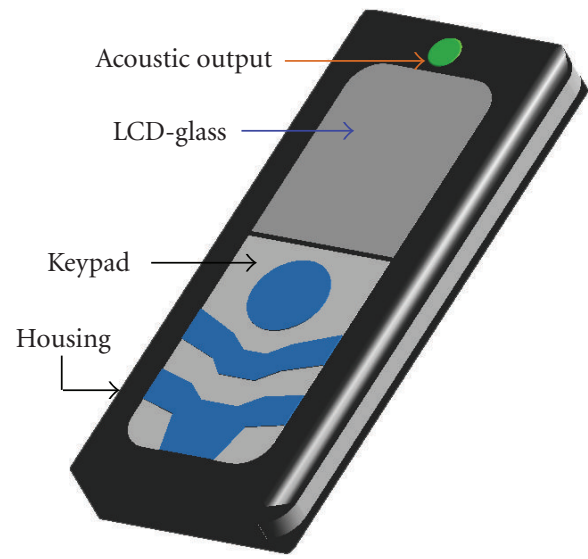

(a)

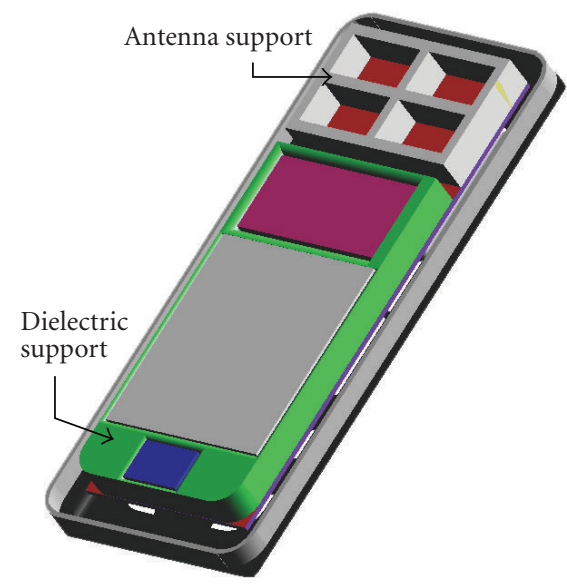

(c)

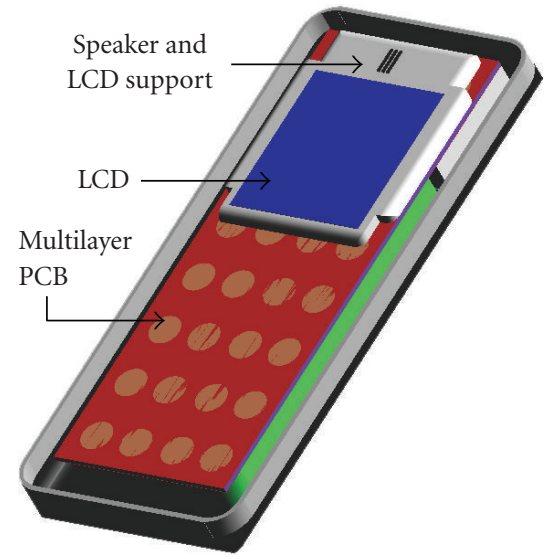

(b)

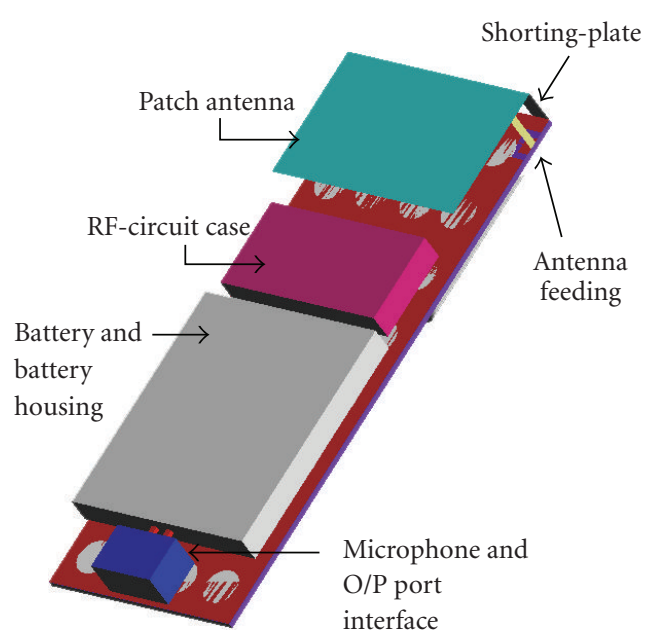

(d)

FIGURE 2: The SEMCAD X representation of the handset with internal antenna (model-B1) showing different components and parts in different views.

operating at different frequencies, that is, 900,1800 , and $2025 \mathrm{MHz}$.

The handset parts and components are not located identically in all models due to the different antenna position and size regarding each different operating frequency. Figure 2 demonstrates the SEMCAD $X$ representation of handset model-B1, where different parts and components are shown in different views. Figure 3 shows the structure of the rectangular patch antenna with shorting plate. The plastic back-cover of the handset touches the patch antenna, where no air gap exists between them. The maximum physical dimensions of the handset with internal patch antenna are $110 \mathrm{~mm} \times 44 \mathrm{~mm} \times 13 \mathrm{~mm}$, whereas; the multilayer PCB dimensions are $97 \mathrm{~mm} \times 37 \mathrm{~mm} \times 1 \mathrm{~mm}$. The dimensions of the patch antenna at 900,1800 , and $1800 \mathrm{MHz}$ are illustrated in Figure 3, where the width of the shorting plate is $3.5 \mathrm{~mm}$.

\subsection{Hand model}

A semirealistic hand model consisting of three tissues (skin, muscle, and bone) [20-22] is designed with two common different holding positions referred later as hand 1 and hand2. Hand1 is grasping the lower part of the handset, whereas hand2 is grasping the upper part of the handset. These proposed hand-holds represent the two applicable extremes of hand holding. The electrical properties and densities of the hand tissues are given in Table 2.

\subsection{Head model}

A heterogeneous high-resolution European female head (HR-EFH) model with pressed ears [31], available with Schmidt \& Partner Engineering AG (SPEAG, Zurich, Switzerland ) [27], is used. This MRI-based model consists of 121 different slices, with slice thicknesses of $1 \mathrm{~mm}$ (ear region) and $3 \mathrm{~mm}$ and a transverse spatial resolution of $0.2 \mathrm{~mm}$. Twenty five different tissues are recognized and their electrical properties and densities are given in Table 2. Head and hand tissue properties are set according to material properties and densities database in [27] and to those given in [32], where both are based on [33]. 
TABLE 2: Values of hand, HR-EFH, and SAM material parameters (relative permittivity $\varepsilon_{r}$, electrical conductivity $\sigma$, density $\rho$ ) used for simulations at 900, 1800, and $2025 \mathrm{MHz}$.

\begin{tabular}{|c|c|c|c|c|c|c|c|}
\hline \multirow{2}{*}{ Hand Tissue } & \multicolumn{2}{|c|}{$900 \mathrm{MHz}$} & \multicolumn{2}{|c|}{$1800 \mathrm{MHz}$} & \multicolumn{2}{|c|}{$2025 \mathrm{MHz}$} & \multirow{2}{*}{$\rho\left(\mathrm{kg} / \mathrm{m}^{3}\right)$} \\
\hline & $\varepsilon_{r}$ & $\sigma(\mathrm{S} / \mathrm{m})$ & $\varepsilon_{r}$ & $\sigma(\mathrm{S} / \mathrm{m})$ & $\varepsilon_{r}$ & $\sigma(\mathrm{S} / \mathrm{m})$ & \\
\hline Hand skin & 41.41 & 0.87 & 38.87 & 1.18 & 38.53 & 1.28 & 1100 \\
\hline Hand muscle & 55.03 & 0.94 & 53.55 & 1.34 & 53.26 & 1.47 & 1041 \\
\hline Hand bone & 12.45 & 0.14 & 11.78 & 0.28 & 11.64 & 0.31 & 1990 \\
\hline HR-EFH Tissue & $\varepsilon_{r}$ & $\sigma(\mathrm{S} / \mathrm{m})$ & $\varepsilon_{r}$ & $\sigma(\mathrm{S} / \mathrm{m})$ & $\varepsilon_{r}$ & $\sigma(\mathrm{S} / \mathrm{m})$ & $\rho\left(\mathrm{kg} / \mathrm{m}^{3}\right)$ \\
\hline Air & 1.000 & 0.00 & 1.00 & 0.000 & 1.00 & 0.000 & 1.16 \\
\hline Blood vessel & 44.78 & 0.70 & 43.34 & 1.07 & 43.06 & 1.18 & 1050 \\
\hline Bone (ramus of mandible) & 12.45 & 0.14 & 11.78 & 0.28 & 11.64 & 0.31 & 1990 \\
\hline Brain/gray matter & 52.73 & 0.94 & 50.08 & 1.39 & 49.65 & 1.53 & 1039 \\
\hline Brain/white matter & 38.89 & 0.59 & 37.01 & 0.91 & 36.70 & 1.01 & 1043 \\
\hline Cerebellum & 49.44 & 1.26 & 46.11 & 1.71 & 45.62 & 1.84 & 1040 \\
\hline Cerebro Spinal Fluid (CSF) & 68.64 & 2.41 & 67.20 & 2.92 & 66.87 & 3.09 & 1007 \\
\hline Ear (cartilage) & 42.65 & 0.78 & 40.22 & 1.29 & 39.70 & 1.44 & 1100 \\
\hline Eye-cornea & 55.24 & 1.39 & 52.77 & 1.86 & 52.34 & 2.00 & 1032 \\
\hline Eye-lens & 46.57 & 0.79 & 45.35 & 1.15 & 45.10 & 1.26 & 1090 \\
\hline Eye-vitreous body & 68.90 & 1.64 & 68.57 & 2.03 & 68.46 & 2.17 & 1009 \\
\hline Fat (average infiltrated) & 11.33 & 0.11 & 11.02 & 0.19 & 10.95 & 0.22 & 916 \\
\hline Jaw bone (mandible) & 12.45 & 0.14 & 11.78 & 0.28 & 11.64 & 0.31 & 1990 \\
\hline Mastoid cells (bones) & 5.50 & 0.04 & 5.370 & 0.07 & 5.340 & 0.08 & 980 \\
\hline Midbrain (mesencephalon) & 45.79 & 0.76 & 43.00 & 1.20 & 43.00 & 1.00 & 1039 \\
\hline Muscles & 55.03 & 0.94 & 53.55 & 1.34 & 53.26 & 1.47 & 1041 \\
\hline Nasal cavity (mucous membrane) & 46.08 & 0.84 & 43.85 & 1.23 & 43.48 & 1.35 & 1050 \\
\hline Parotid gland & 59.68 & 1.04 & 58.14 & 1.50 & 57.81 & 1.65 & 1050 \\
\hline Skin & 41.41 & 0.87 & 38.87 & 1.18 & 38.53 & 1.28 & 1100 \\
\hline Skull & 16.62 & 0.24 & 15.56 & 0.43 & 15.35 & 0.49 & 1645 \\
\hline Spinal cord & 32.53 & 0.57 & 30.87 & 0.84 & 30.60 & 0.92 & 1038 \\
\hline Spine & 12.45 & 0.14 & 11.78 & 0.28 & 11.64 & 0.31 & 1990 \\
\hline Thalamus & 45.79 & 0.76 & 43.00 & 1.20 & 43.00 & 1.00 & 1039 \\
\hline Tongue & 55.27 & 0.94 & 53.57 & 1.37 & 53.23 & 1.51 & 1041 \\
\hline Ventricles (brain) & 68.64 & 2.41 & 67.20 & 2.92 & 66.87 & 3.09 & 1007 \\
\hline SAM phantom material & $\varepsilon_{r}$ & $\sigma(\mathrm{S} / \mathrm{m})$ & $\varepsilon_{r}$ & $\sigma(\mathrm{S} / \mathrm{m})$ & $\varepsilon_{r}$ & $\sigma(\mathrm{S} / \mathrm{m})$ & $\rho\left(\mathrm{kg} / \mathrm{m}^{3}\right)$ \\
\hline SAM head shell & 5.0 & 0.0016 & 5.0 & 0.0016 & 5.0 & 0.0016 & 1030 \\
\hline SAM head liquid & 41.5 & 0.97 & 40.0 & 1.4 & 40.0 & 1.4 & 1030 \\
\hline
\end{tabular}

For comparison, an SAM phantom developed by different standard committees $[1,3-6]$ is also used to simulate the human head. The electrical properties of the SAM materials are defined in $[1,34]$ and given in Table 2.

Figure 4 exhibits different holding positions of the handset models close to HR-EFH at cheek position indicating the coordinate system, where the acoustic output is set opposite to earpiece center in compliance with IEEE Std. 1528 [1]. Due to different antenna types/positions considered in simulations, the distances between the antennas feed points and the nearest head-tissue voxel also differ. According to the acoustic output position at the origin point $(x=0, y=$ 0 , and $z=0 \mathrm{~mm}$ ) and with the different coordinate systems arrangement for each antenna type (Figure 4), the antenna feed position is at $(x=17, y=-11$, and $z=-8.5 \mathrm{~mm})$ for model-A1; at $(x=-17, y=-11$, and $z=-8.5 \mathrm{~mm})$ for model-A2, whereas it is at $(x=15, y=-3$, and $z=$
$5.4 \mathrm{~mm})$ for model-B1; and at $(x=15, y=-89.5$, and $z=$ $5.4 \mathrm{~mm}$ ) for model-B2.

\section{FDTD-GRID GENERATION AND SIMULATION PARAMETERS}

The simulation platform SEMCAD $X$ incorporates automated heterogeneous grid generation, which automatically adapts the mesh to a specific setup. The most crucial parts with respect to grid resolution are the antenna, as well as the PCB with its thin PEC ground layers ( $110 \mu \mathrm{m}$ thickness).

To align the simulated handset components to the FDTD grid accurately, a minimum spatial resolution of $0.5 \times 0.5 \times$ $0.5 \mathrm{~mm}^{3}$ and a maximum spatial resolution of $10 \times 10 \times$ $10 \mathrm{~mm}^{3}$ in the $x, y$, and $z$ directions are chosen for simulating the handset in hand close to head. Depending on the case complexity, a refining factor of (5-20) with grading ratio of 
TABLE 3: The generated FDTD grid cell size of the studied handset models in free space and in hand close to HR-EFH at different positions operating at 900,1800 , and $2025 \mathrm{MHz}$.

\begin{tabular}{|c|c|c|c|c|c|c|c|c|}
\hline \multirow{2}{*}{\multicolumn{3}{|c|}{$\begin{array}{c}\text { FDTD-grid cell size (Mcells) } \\
\text { Handset model }\end{array}$}} & \multicolumn{2}{|c|}{$900 \mathrm{MHz}$} & \multicolumn{2}{|c|}{$1800 \mathrm{MHz}$} & \multicolumn{2}{|c|}{$2025 \mathrm{MHz}$} \\
\hline & & & A1 & $\mathrm{A} 2$ & A1 & A2 & A1 & A2 \\
\hline \multirow{5}{*}{ HR-EFH } & In free $s$ & & 0.73372 & 0.73372 & 0.47925 & 0.47925 & 0.89113 & 0.89113 \\
\hline & \multirow{2}{*}{ Cheek } & Hand1 & 19.841 & 19.9055 & 18.07 & 18.1998 & 12.9027 & 13.1749 \\
\hline & & Hand2 & 18.513 & 18.7085 & 16.6208 & 16.2842 & 11.8514 & 12.3738 \\
\hline & \multirow{2}{*}{ Tilt } & Hand1 & 20.7561 & 20.9639 & 19.3401 & 19.2665 & 18.9213 & 18.695 \\
\hline & & Hand 2 & 19.6181 & 19.6262 & 17.852 & 17.6552 & 17.4448 & 17.4434 \\
\hline \multicolumn{3}{|c|}{ Handset model } & B1 & B2 & B1 & B2 & B1 & B2 \\
\hline \multicolumn{3}{|c|}{ In free space } & 1.176 & 1.20755 & 1.04378 & 1.22912 & 1.04378 & 1.08768 \\
\hline \multirow{4}{*}{ HR-EFH } & \multirow{2}{*}{ Cheek } & Hand 1 & 19.4184 & 18.7987 & 19.2137 & 19.9362 & 19.0769 & 19.0168 \\
\hline & & Hand2 & 17.6703 & 17.6138 & 17.1771 & 19.0242 & 17.1164 & 18.2577 \\
\hline & \multirow{2}{*}{ Tilt } & Hand1 & 21.8594 & 22.0785 & 20.9776 & 21.93 & 21.1931 & 21.4403 \\
\hline & & Hand2 & 20.3798 & 20.8524 & 19.0882 & 19.7979 & 19.2979 & 19.4936 \\
\hline
\end{tabular}

TABLE 4: Computational results of the antenna input impedance, $Z_{\text {in }},\left|S_{11}\right|$ in $\mathrm{dB}$, radiation efficiency, $\eta_{\mathrm{rad}}$, and total efficiency, $\eta_{\text {tot }}$, for different handset setups at $900 \mathrm{MHz}$.

\begin{tabular}{|c|c|c|c|c|c|c|c|c|c|c|}
\hline \multirow{2}{*}{\multicolumn{3}{|c|}{ Parameter }} & \multicolumn{8}{|c|}{ Frequency/900 MHz } \\
\hline & & & \multicolumn{2}{|c|}{$Z_{\text {in }}(\mathrm{Ohm})$} & \multicolumn{2}{|c|}{$\left|S_{11}\right|(\mathrm{dB})$} & \multicolumn{2}{|c|}{$\eta_{\mathrm{rad}}(\%)$} & \multicolumn{2}{|c|}{$\eta_{\text {tot }}(\%)$} \\
\hline \multicolumn{3}{|c|}{ Handset model } & A1 & $\mathrm{A} 2$ & A1 & A2 & $\mathrm{A} 1$ & $\mathrm{~A} 2$ & A1 & A2 \\
\hline \multicolumn{3}{|c|}{ In free space } & $44.5+j 0.86$ & $44.5+j 0.86$ & -24.4 & -24.4 & 77.8 & 77.8 & 77.6 & 77.6 \\
\hline \multirow[t]{2}{*}{ No head } & \multicolumn{2}{|c|}{ In hand1 } & $49.2-j 8.17$ & $51.3-j 9.55$ & -21.6 & -20.5 & 89.8 & 60.3 & 87.2 & 59.8 \\
\hline & \multicolumn{2}{|c|}{ In hand 2} & $78.5+j 37.4$ & $58.36-j 3.5$ & -9.1 & -21.5 & 30.7 & 36.5 & 26.9 & 36.3 \\
\hline \multirow{4}{*}{ HR-EFH } & \multirow{2}{*}{ Cheek } & Hand1 & $42.7+j 4.63$ & $42.6+j 4.27$ & -20.6 & -20.8 & 18.7 & 21.2 & 18.5 & 21.0 \\
\hline & & Hand2 & $57.7+j 46.9$ & $44.1+\mathrm{j} 10.9$ & -7.9 & -17.6 & 10.3 & 10.7 & 8.60 & 10.6 \\
\hline & \multirow{2}{*}{ Tilt } & Hand 1 & $48.1+\mathrm{j} 2.25$ & $47.0-\mathrm{j} 0.49$ & -30.4 & -30.1 & 29.1 & 30.7 & 29.1 & 30.7 \\
\hline & & Hand2 & $66.7+j 46.7$ & $52.2+\mathrm{j} 10.1$ & -8.1 & -19.9 & 16.2 & 17.1 & 13.6 & 16.9 \\
\hline \multicolumn{3}{|c|}{ Handset model } & $\mathrm{B} 1$ & $\mathrm{~B} 2$ & $\mathrm{~B} 1$ & B2 & $\mathrm{B} 1$ & $\mathrm{~B} 2$ & B1 & B2 \\
\hline \multicolumn{3}{|c|}{ In free space } & $49.6-j 11.7$ & $50.6-j 6.92$ & -18.7 & -23.2 & 83.2 & 83.9 & 82.1 & 83.5 \\
\hline \multirow[t]{2}{*}{ No head } & \multicolumn{2}{|c|}{ In hand1 } & $60.4-j 0.32$ & $24.4+j 11.7$ & -20.5 & -8.5 & 64.5 & 62.6 & 63.9 & 53.8 \\
\hline & \multicolumn{2}{|c|}{ In hand 2} & $17.0+j 36.2$ & $17.7+j 34.6$ & -3.8 & -4.1 & 35.5 & 37.5 & 20.9 & 23.0 \\
\hline \multirow{4}{*}{ HR-EFH } & \multirow{2}{*}{ Cheek } & Hand 1 & $57.7-\mathrm{j} 17.5$ & $30.1+j 13.5$ & -15.1 & -10.6 & 25.5 & 35.6 & 24.7 & 32.5 \\
\hline & & Hand2 & $22.6+j 32.6$ & $17.9+j 32.6$ & -5.4 & -4.3 & 14.6 & 19.8 & 10.4 & 12.5 \\
\hline & \multirow{2}{*}{ Tilt } & Hand 1 & $57.2-\mathrm{j} 13.4$ & $30.3+14.3$ & -17.0 & -10.5 & 37.9 & 44.5 & 37.1 & 40.5 \\
\hline & & Hand 2 & $19.6+j 32.9$ & $15.4+j 33.9$ & -4.7 & -3.6 & 19.4 & 27.4 & 12.8 & 15.5 \\
\hline
\end{tabular}

(1.2-1.3) is used for the solid regions during the simulations. The simulations assume a steady-state voltage at 900, 1800, and $2025 \mathrm{MHz}$, with a feed point of $50 \mathrm{Ohm}$ voltage source of $0.5 \mathrm{~mm}$ physical gap. The absorbing boundary conditions (ABCs) are set as a uniaxial perfectly matched layer (UPML) mode with a very high strength thickness, where minimum level of absorption at the outer boundary is (>99.9\%) [27].

Table 3 lists the total number of FDTD-grid cells required to simulate the handset models in free space and in hand close to head at different positions operating at 900, 1800, and $2025 \mathrm{MHz}$.

\section{EM INTERACTION BETWEEN HANDSET AND HUMAN}

The EM interaction between handset antenna and human is evaluated, firstly, by assessing the effect of human head and hand on the handset antenna performance through computing the antenna parameters including the input impedance $\left(Z_{\text {in }}\right),\left|S_{11}\right|$ in $\mathrm{dB}$, radiation efficiency $\left(\eta_{\mathrm{rad}}\right)$, total efficiency $\left(\eta_{\text {tot }}\right)$, and the total isotropic sensitivity (TIS), secondly, by assessing the impact of antenna EM radiation on head and hand through computing the SAR and power absorption in tissues.

\subsection{Antenna performance}

The results in Table 4 show the computed antenna parameters including $Z_{\text {in }},\left|S_{11}\right|$ in $\mathrm{dB}, \eta_{\mathrm{rad}}$, and $\eta_{\text {tot }}$ of the handset models at $900 \mathrm{MHz}$ under different usage patterns in a presence of HR-EFH model, whereas the results in Tables 5 and 6 show the antenna parameters at 1800 and $2025 \mathrm{MHz}$, 
TABLE 5: Computational results of the antenna input impedance, $Z_{\text {in }}$, $\left|S_{11}\right|$ in $\mathrm{dB}$, radiation efficiency, $\eta_{\text {rad }}$, and total efficiency, $\eta_{\text {tot }}$, for different handset setups at $1800 \mathrm{MHz}$.

\begin{tabular}{|c|c|c|c|c|c|c|c|c|c|c|}
\hline \multirow{2}{*}{\multicolumn{3}{|c|}{ Parameter }} & \multicolumn{8}{|c|}{ Frequency/1800 MHz } \\
\hline & & & \multicolumn{2}{|c|}{$Z_{\text {in }}(\mathrm{Ohm})$} & \multicolumn{2}{|c|}{$\left|S_{11}\right|(\mathrm{dB})$} & \multicolumn{2}{|c|}{$\eta_{\mathrm{rad}}(\%)$} & \multicolumn{2}{|c|}{$\eta_{\text {tot }}(\%)$} \\
\hline \multicolumn{3}{|c|}{ Handset model } & A1 & $\mathrm{A} 2$ & A1 & A2 & A1 & $\mathrm{A} 2$ & A1 & $\mathrm{A} 2$ \\
\hline \multicolumn{3}{|c|}{ In free space } & $38.7+j 9.92$ & $38.7+j 9.92$ & -15.5 & -15.5 & 89.8 & 89.8 & 87.3 & 87.3 \\
\hline \multirow[t]{2}{*}{ No head } & \multicolumn{2}{|c|}{ In hand1 } & $38.5+j 9.07$ & $56.2+j 0.82$ & -15.6 & -24.6 & 52.2 & 62.1 & 50.8 & 61.9 \\
\hline & \multicolumn{2}{|c|}{ In hand2 } & $98.7+j 26.4$ & $41.7+j 5.52$ & -8.7 & -19.3 & 27.8 & 42.4 & 24.8 & 41.9 \\
\hline \multirow{4}{*}{ HR-EFH } & \multirow{2}{*}{ Cheek } & Hand 1 & $43.9+j 17.9$ & $61.7+j 18.1$ & -14.1 & -14.4 & 17.5 & 30.1 & 16.8 & 29.0 \\
\hline & & Hand2 & $106+j 47.2$ & $45.6+j 16.3$ & -7.0 & -15.2 & 9.6 & 20.0 & 7.6 & 19.4 \\
\hline & \multirow{2}{*}{ Tilt } & Hand 1 & $43.7+j 22.5$ & $64.1+j 22.0$ & -12.3 & -13.0 & 20.1 & 30.1 & 18.9 & 28.6 \\
\hline & & Hand2 & $106+j 50.3$ & $44.5+\mathrm{j} 18.2$ & -6.8 & -14.1 & 11.1 & 19.1 & 8.8 & 18.3 \\
\hline \multicolumn{3}{|c|}{ Handset model } & B1 & B2 & B1 & B2 & B1 & B2 & B1 & $\mathrm{B} 2$ \\
\hline \multicolumn{3}{|c|}{ In free space } & $33.3-j 9.97$ & $38.9-\mathrm{j} 8.72$ & -12.7 & -16.0 & 90.0 & 86.4 & 85.1 & 84.2 \\
\hline \multirow[t]{2}{*}{ No head } & \multicolumn{2}{|c|}{ In hand1 } & $36.7-j 6.13$ & $58.7+j 23.3$ & -15.5 & -13.0 & 54.0 & 41.2 & 52.4 & 39.1 \\
\hline & \multicolumn{2}{|c|}{ In hand2 } & $49.2+j 36.5$ & $42.9+j 6.88$ & -9.2 & -19.5 & 31.1 & 37.2 & 27.4 & 36.7 \\
\hline \multirow{4}{*}{ HR-EFH } & \multirow{2}{*}{ Cheek } & Hand1 & $37.9+j 7.64$ & $61.1+j 25.5$ & -15.8 & -12.3 & 22.9 & 22.9 & 22.3 & 21.5 \\
\hline & & Hand2 & $48.6+j 52.0$ & $52.8+j 6.65$ & -6.6 & -23.1 & 15.6 & 13.9 & 12.2 & 13.8 \\
\hline & \multirow{2}{*}{ Tilt } & Hand1 & $32.9-\mathrm{j} 1.25$ & $59.3+j 24.9$ & -13.6 & -12.5 & 24.4 & 26.5 & 23.3 & 25.0 \\
\hline & & Hand2 & $42.0+j 41.4$ & $40.3+j 9.6$ & -7.6 & -16.5 & 17.7 & 22.3 & 14.6 & 21.8 \\
\hline
\end{tabular}

TABLe 6: Computational results of the antenna input impedance, $Z_{\text {in }},\left|S_{11}\right|$ in $\mathrm{dB}$, radiation efficiency, $\eta_{\text {rad }}$, and total efficiency, $\eta_{\text {tot }}$, for different handset setups at $2025 \mathrm{MHz}$.

\begin{tabular}{|c|c|c|c|c|c|c|c|c|c|c|}
\hline \multirow{2}{*}{\multicolumn{3}{|c|}{ Parameter }} & \multicolumn{8}{|c|}{ Frequency/2025 MHz } \\
\hline & & & \multicolumn{2}{|c|}{$Z_{\text {in }}(\mathrm{Ohm})$} & \multicolumn{2}{|c|}{$\left|S_{11}\right|(\mathrm{dB})$} & \multicolumn{2}{|c|}{$\eta_{\mathrm{rad}}(\%)$} & \multicolumn{2}{|c|}{$\eta_{\text {tot }}(\%)$} \\
\hline \multicolumn{3}{|c|}{ Handset model } & A1 & $\mathrm{A} 2$ & A1 & A2 & A1 & $\mathrm{A} 2$ & $\mathrm{~A} 1$ & $\mathrm{~A} 2$ \\
\hline \multicolumn{3}{|c|}{ In free space } & $41.8+j 12.3$ & $41.8+j 12.3$ & -15.9 & -15.9 & 92.0 & 92.0 & 89.6 & 89.6 \\
\hline \multicolumn{3}{|c|}{ In hand1 } & $37.6+\mathrm{j} 11.2$ & $49.4+j 2.06$ & -14.4 & -33.3 & 55.4 & 65.5 & 53.5 & 65.4 \\
\hline & \multicolumn{2}{|c|}{ In hand2 } & $72.4+j 28.4$ & $36.4+\mathrm{j} 10.1$ & -10.8 & -14.2 & 32.0 & 46.1 & 29.3 & 44.3 \\
\hline \multirow{4}{*}{ HR-EFH } & \multirow{2}{*}{ Cheek } & Hand 1 & $42.3+j 16.8$ & $61.5+j 8.64$ & -14.1 & -17.8 & 19.1 & 32.0 & 18.4 & 31.4 \\
\hline & & Hand2 & $82.8+j 40.9$ & $45.4+\mathrm{j} 17.0$ & -8.5 & -14.8 & 10.5 & 19.0 & 9.0 & 18.3 \\
\hline & \multirow{2}{*}{ Tilt } & Hand 1 & $43.6+j 20.9$ & $60.1+j 9.4$ & -12.8 & -18.1 & 22.3 & 33.0 & 21.1 & 32.5 \\
\hline & & Hand2 & $82.1+\mathrm{j} 44.6$ & $45.7+\mathrm{j} 18.1$ & -8.1 & -14.4 & 11.9 & 20.1 & 10.1 & 19.3 \\
\hline \multicolumn{3}{|c|}{ Handset model } & $\mathrm{B} 1$ & $\mathrm{~B} 2$ & $\mathrm{~B} 1$ & B2 & B1 & $\mathrm{B} 2$ & $\mathrm{~B} 1$ & $\mathrm{~B} 2$ \\
\hline \multicolumn{3}{|c|}{ In free space } & $42.7-\mathrm{j} 1.80$ & $45.5+j 4.0$ & -21.8 & -23.9 & 94.6 & 94.0 & 94.0 & 93.6 \\
\hline \multirow[t]{2}{*}{ No head } & \multicolumn{2}{|c|}{ In hand1 } & $49.4-j 0.33$ & $70.1+j 36.5$ & -43.1 & -9.6 & 67.0 & 32.8 & 67.0 & 29.2 \\
\hline & \multicolumn{2}{|c|}{ In hand2 } & $73.4+j 62.7$ & $50.6+j 25.3$ & -6.3 & -12.2 & 33.0 & 38.6 & 25.3 & 36.3 \\
\hline \multirow{4}{*}{ HR-EFH } & \multirow{2}{*}{ Cheek } & Hand 1 & $49.9+j 5.50$ & $73.2+j 38.6$ & -25.2 & -9.1 & 26.8 & 16.7 & 26.7 & 14.6 \\
\hline & & Hand2 & $74.5+j 75.0$ & $59.3+\mathrm{J} 21.1$ & -5.3 & -13.7 & 12.0 & 16.6 & 8.5 & 15.4 \\
\hline & \multirow{2}{*}{ Tilt } & Hand 1 & $40.7+j 2.92$ & $72.6+j 37.6$ & -19.3 & -9.3 & 28.8 & 20.9 & 28.5 & 18.5 \\
\hline & & Hand2 & $63.4+\mathrm{J} 67.5$ & $50.4+j 38.6$ & -5.6 & -9.1 & 14.2 & 25.0 & 10.3 & 23.2 \\
\hline
\end{tabular}

respectively. The $\eta_{\text {tot }}$ is given by

$$
\eta_{\mathrm{tot}}=\eta_{\mathrm{mis}} \eta_{\mathrm{rad}}
$$

where $\eta_{\text {mis }}$ represents the mismatch efficiency and equal to

$$
\eta_{\text {mis }}=\left(1-\left|S_{11}\right|^{2}\right)
$$

Figure 5 illustrates the 3D far-field radiation pattern of the handset model-A1 in free space as well as in hand1 close to head (SAM and HR-EFH) at cheek position and operating at 900, 1800, and $2025 \mathrm{MHz}$, whereas Figure 6 illustrates the $3 \mathrm{D}$ far-field radiation pattern of the handset modelB1 in the same conditions. In both Figures 5 and 6, the antenna feeding source position considered as the origin of the antenna pattern coordinate system, that is, $x=0, y=$ 0 , and $z=0 \mathrm{~mm}$.

\subsection{Total isotropic sensitivity}

The TIS is a measure of the handset receiving performance, where both TIS and total radiated power (TRP) together 
TABLE 7: The total isotropic sensitivity (TIS) levels of the handset models for different setups at 900, 1800, and $2025 \mathrm{MHz}$.

\begin{tabular}{|c|c|c|c|c|c|c|c|c|}
\hline & \multirow{2}{*}{$\frac{\text { TIS }(\mathrm{dBm})}{\text { Handset model }}$} & & \multicolumn{2}{|c|}{$900 \mathrm{MHz}$} & \multicolumn{2}{|c|}{$1800 \mathrm{MHz}$} & \multicolumn{2}{|c|}{$2025 \mathrm{MHz}$} \\
\hline & & & A1 & A2 & A1 & A2 & A1 & A2 \\
\hline & In free space & & -104.9 & -104.9 & -105.4 & -105.4 & -105.5 & -105.5 \\
\hline & In hand1 & & -103.6 & -103.8 & -103.1 & -103.9 & -103.3 & -104.2 \\
\hline & In hand2 & & -100.3 & -101.6 & -99.8 & -102.2 & -100.7 & -102.5 \\
\hline \multirow{4}{*}{$\mathrm{HR}-\mathrm{EFH}$} & \multirow{2}{*}{ Cheek } & Hand1 & -98.7 & -99.2 & -98.3 & -100.6 & -98.7 & -101.0 \\
\hline & & Hand2 & -95.4 & -96.3 & -94.9 & -98.9 & -95.6 & -98.6 \\
\hline & \multirow{2}{*}{ Tilt } & Hand1 & -100.6 & -100.9 & -98.8 & -100.6 & -99.3 & -101.1 \\
\hline & & Hand2 & -97.4 & -98.3 & -95.5 & -98.7 & -96.0 & -98.9 \\
\hline & Handset model & & B1 & B2 & B1 & B2 & B1 & B2 \\
\hline & In free space & & -105.2 & -105.2 & -105.3 & -105.3 & -105.7 & -105.7 \\
\hline & In hand1 & & -104.2 & -103.3 & -103.2 & -101.9 & -104.3 & -100.7 \\
\hline & In hand2 & & -99.1 & -99.6 & -100.4 & -101.7 & -100 & -101.6 \\
\hline \multirow{4}{*}{ HR-EFH } & \multirow{2}{*}{ Cheek } & Hand1 & -100 & -101.1 & -99.5 & -99.3 & -100.3 & -97.7 \\
\hline & & Hand2 & -96.2 & -97.0 & -96.9 & -97.4 & -95.2 & -97.9 \\
\hline & \multirow{2}{*}{ Tilt } & Hand1 & -101.7 & -102.1 & -99.7 & -100 & -100.6 & -98.7 \\
\hline & & Hand2 & -97.1 & -97.9 & -97.7 & -99.4 & -96.2 & -99.7 \\
\hline
\end{tabular}

TABLE 8: Pooled statistics of peak 1 and $10 \mathrm{~g}$ SAR in tissues, radiated power, absorbed power in tissues, dielectric loss, and power budget error for the handset models in hand closed to HR-EFH at different positions operating at $900 \mathrm{MHz}$.

\begin{tabular}{|c|c|c|c|c|c|c|c|c|c|}
\hline \multirow{3}{*}{\multicolumn{2}{|c|}{$\begin{array}{l}\text { Handset model } \\
\text { Hand position }\end{array}$}} & \multicolumn{8}{|c|}{ Frequency/900 MHz } \\
\hline & & \multicolumn{2}{|c|}{ A1 } & \multicolumn{2}{|c|}{ A2 } & \multicolumn{2}{|c|}{ B1 } & \multicolumn{2}{|c|}{ B2 } \\
\hline & & hand1 & hand2 & hand1 & hand2 & hand1 & hand 2 & hand1 & hand2 \\
\hline \multicolumn{2}{|c|}{ Antenna input power $(\mathrm{mW})$} & 600 & 600 & 600 & 600 & 600 & 600 & 600 & 600 \\
\hline \multirow{9}{*}{ Cheek-position } & $\mathrm{SAR}_{\mathrm{lg}}$ in head $(\mathrm{W} / \mathrm{kg})$ & 3.38 & 2.52 & 2.77 & 2.51 & 4.87 & 3.23 & 2.21 & 3.07 \\
\hline & $\mathrm{SAR}_{10 \mathrm{~g}}$ in head $(\mathrm{W} / \mathrm{kg})$ & 1.90 & 1.76 & 2.01 & 1.94 & 2.52 & 2.37 & 1.74 & 2.42 \\
\hline & $\mathrm{SAR}_{\mathrm{lg}}$ in hand $(\mathrm{W} / \mathrm{kg})$ & 1.54 & 5.16 & 1.46 & 3.62 & 0.79 & 6.37 & 4.06 & 5.47 \\
\hline & Radiated power (mW) & 111.0 & 51.6 & 125.9 & 63.4 & 148.6 & 62.6 & 194.8 & 75.2 \\
\hline & Absorbed power in head ( $\mathrm{mW})$ & 250.4 & 209.1 & 247.3 & 214.7 & 280.3 & 229.3 & 183.3 & 245.3 \\
\hline & Absorption rate in head (\%) & 41.7 & 34.8 & 41.2 & 35.8 & 46.7 & 38.2 & 30.5 & 40.9 \\
\hline & Absorbed power in hand ( $\mathrm{mW})$ & 97.5 & 208.3 & 86.4 & 182.6 & 48.6 & 260.2 & 146.2 & 229.8 \\
\hline & Dielectric loss (mW) & 135.0 & 119.6 & 134.5 & 131.5 & 115.6 & 36.1 & 63.7 & 36.9 \\
\hline & Power budget error (\%) & 1.01 & 1.90 & 0.98 & 1.30 & 1.15 & 1.94 & 1.99 & 2.13 \\
\hline \multirow{9}{*}{ Tilt-position } & $\mathrm{SAR}_{\mathrm{lg}}$ in head (W/kg) & 2.61 & 1.99 & 2.04 & 1.90 & 3.19 & 2.04 & 0.91 & 1.52 \\
\hline & $\mathrm{SAR}_{10 \mathrm{~g}}$ in head $(\mathrm{W} / \mathrm{kg})$ & 1.10 & 0.97 & 1.17 & 1.10 & 1.45 & 1.36 & 0.73 & 1.20 \\
\hline & $\mathrm{SAR}_{\mathrm{lg}}$ in hand $(\mathrm{W} / \mathrm{kg})$ & 1.86 & 5.11 & 1.72 & 4.40 & 1.12 & 7.00 & 4.25 & 7.30 \\
\hline & Radiated power $(\mathrm{mW})$ & 174.4 & 81.9 & 184.3 & 101.4 & 222.7 & 76.9 & 243.3 & 93.1 \\
\hline & Absorbed power in head (mW) & 184.6 & 159.2 & 185.3 & 160.6 & 193.8 & 195.6 & 130.3 & 166.0 \\
\hline & Absorption rate in head (\%) & 30.8 & 26.5 & 30.9 & 26.8 & 32.3 & 32.6 & 21.7 & 27.7 \\
\hline & Absorbed power in hand ( $\mathrm{mW})$ & 114.0 & 237.1 & 99.4 & 213.5 & 77.0 & 280.0 & 159.0 & 291.4 \\
\hline & Dielectric loss (mW) & 122.5 & 110.0 & 126.2 & 117.3 & 104.8 & 35.0 & 63.9 & 38.7 \\
\hline & Power budget error $(\%)$ & 0.75 & 1.97 & 0.80 & 1.19 & 0.28 & 2.08 & 0.58 & 1.80 \\
\hline
\end{tabular}

determine effectiveness of the handset as a piece of radio equipment, in particular, the maximum range at which the handset can operate from the base station with some given level of performance [35]. As compared with the normal receiver sensitivity in GSM900, a typical specification for the TIS is around 10-dB higher in talk position [36]. The TIS can be measured in reverberation chamber with a definition formula given in [37]. In [38], the sensitivity of a commercially available GSM900 phone in receiving mode was measured in reverberation chamber for different handset setups, that is, in free space and against head phantom. Using SEMCAD X, the computed TIS values for the proposed handset models under different usage patterns are computed as listed in Table 7. 


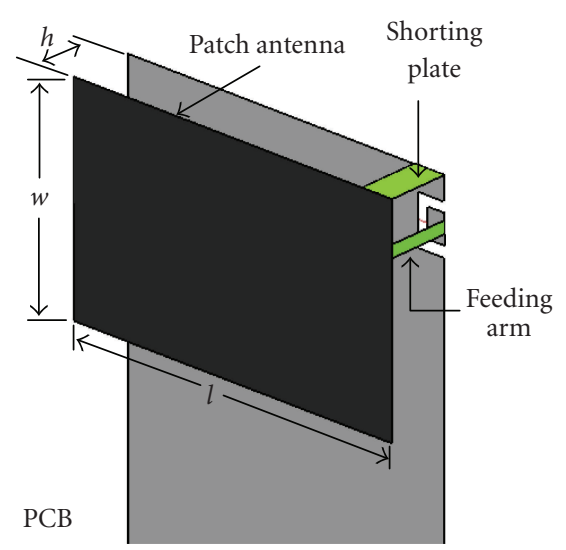

\begin{tabular}{lll}
\multicolumn{1}{c}{$900 \mathrm{MHz}$} & \multicolumn{1}{c}{$1800 \mathrm{MHz}$} & \multicolumn{1}{c}{$2025 \mathrm{MHz}$} \\
$l=37 \mathrm{~mm}$ & $l=22.6 \mathrm{~mm}$ & $l=19.2 \mathrm{~mm}$ \\
$w=23 \mathrm{~mm}$ & $w=12.9 \mathrm{~mm}$ & $w=11.1 \mathrm{~mm}$ \\
$h=6.7 \mathrm{~mm}$ & $h=6.7 \mathrm{~mm}$ & $h=6.7 \mathrm{~mm}$
\end{tabular}

FIGURE 3: The numerical structure of the rectangular patch antenna with shorting plate, used for the handset with internal antenna, and its dimensions at 900, 1800, and $2025 \mathrm{MHz}$.

\subsection{SAR and power absorption computation in tissue}

The influence of the EM wave irradiation on the living body is measured by evaluating the SAR, where SAR is defined as the amount of EM energy absorption in the unit mass as follows [39]:

$$
\operatorname{SAR}=\frac{\sigma_{E}}{\rho}|E|^{2}
$$

Here, $\sigma_{E}(\mathrm{~S} / \mathrm{m})$ represents the electric conductivity, $E(\mathrm{~V} / \mathrm{m})$ the rms electric field strength, and $\rho\left(\mathrm{kg} / \mathrm{m}^{3}\right)$ the mass density of the tissue. An algorithm based on SCC34/SC2/WG2 computational dosimetry (IEEE-1529 [40]), the spatial-peak $\operatorname{SAR}\left(x, y, z, f_{0}\right)$ can be computed over any required mass by using SEMCAD X platform.

The spatial-peak SAR should be evaluated in a cubical volume of the body tissues that is within $5 \%$ of the required mass [27]. The averaged-peak SAR (spatial-peak SAR [IEEE1529]) can be specified over a cube of $1 \mathrm{~g}$ and $10 \mathrm{~g}$ mass, and normalized to a certain source power. Referred to the IEEE standard C95.1b-2004 [41] (for low-power devices, uncontrolled environment), the antenna input power is set as $0.6 \mathrm{~W}$ at $900 \mathrm{MHz}$ and $0.125 \mathrm{~W}$ at both 1800 and $2025 \mathrm{MHz}$ for all handset setups.

The computed values of the peak SAR (averaged over $1 \mathrm{~g}$ and $10 \mathrm{~g}$ ) and power absorption in tissues owing to handsets exposure in different conditions at 900, 1800, and $2025 \mathrm{MHz}$ are listed in Tables 8,9 , and 10 , respectively.

Figures 7 and 8 indicate the sliced-distribution of the averaged-peak $S_{A R}$ in the HR-EFH tissues exposed to $\mathrm{EM}$ radiation of handset models- $\mathrm{A} 1$ and $\mathrm{A} 2$ under different usage patterns at 900 and $1800 \mathrm{MHz}$, respectively, whereas, Figures 9 and 10 indicate the sliced-distribution of the averaged peak $S A R_{1 g}$ due to handset models-B1 and B2 exposure under the same usage patterns at 900 and $1800 \mathrm{MHz}$, respectively.

\section{POWER BUDGET ERROR}

The power budget error is defined as

$$
\begin{gathered}
\text { Power budget error }=\frac{\left|P_{\text {in }}-\left(P_{\mathrm{rad}}+P_{\mathrm{abs}}+P_{\mathrm{Loss}}\right)\right|}{P_{\text {in }}}, \\
P_{\text {Loss }}=P_{d}+P_{c},
\end{gathered}
$$

where $P_{\text {in }}$ is the input power, $P_{\text {rad }}$ the radiation power, $P_{\text {abs }}$ the absorbed power in tissues, and $P_{\text {Loss }}$ the total power loss. $P_{\text {Loss }}$ includes the dielectric loss $P_{d}$ and the metallic ohmic-loss $P_{c}$. Since all metal parts are considered as PEC in simulations, thus $P_{c}=0$ and $P_{\text {Loss }}=P_{d}$. However, (6) was defined by $[21,22,42]$ as the computation error. Even with (6) equals zero, numerical errors, and geometry errors could be still inherent to the numerical analysis. Tables $8-10$ list the power budget error values for both handset types in different conditions and at different frequencies.

\section{DISCUSSION}

The hand impact on the EM interaction between handset antennas and human is investigated profoundly in this paper. Owing to hand-hold alteration under different usage patterns, handsets with external and internal antennas show a significant deviation in their performance as well as in their EM radiation impact on head. Although the user's hand has a negative impact on the antenna performance of a handset in-use, changing its position may reduce the amount of the SAR and power absorption in head tissues.

\subsection{Antenna performance}

The results listed in Tables 4-7 manifest that the handhold position has a considerable impact on the handset antenna matching, antenna radiation efficiency, and the TIS. The impact of hand at different positions on the antenna performance (excluding the TIS) was already presented by $[12,14,16,22,23]$. However, this impact may vary depending on many factors, that is, antenna type/position, handset position with respect to head, and the operating frequency, concluded as follows.

(1) The significant degradation in internal patch antenna performance due to the different hand positions, as compared with the external antenna, is because the patch antenna is sandwiched between hand and head tissues during the practical usage, where the hand tissues act as the antenna upper dielectric layers. This may shift the tuning frequency as well as decrease the radiation efficiency.

(2) Based on the relation between the absolute difference in antenna total efficiency due to hand-hold alteration (from hand1 to hand2) and the antenna/handset position, 


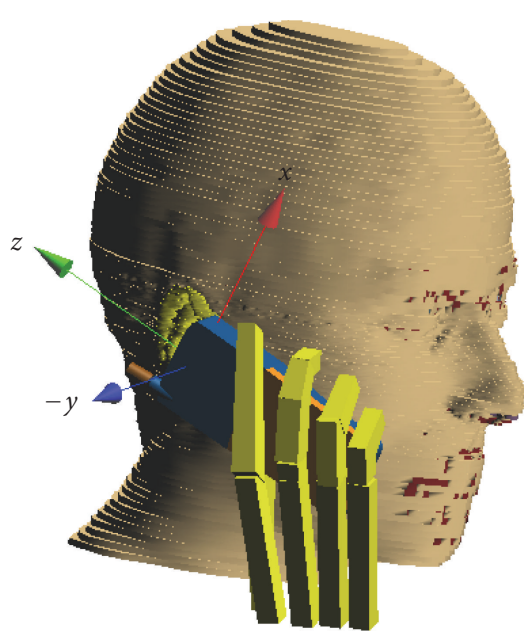

(a)

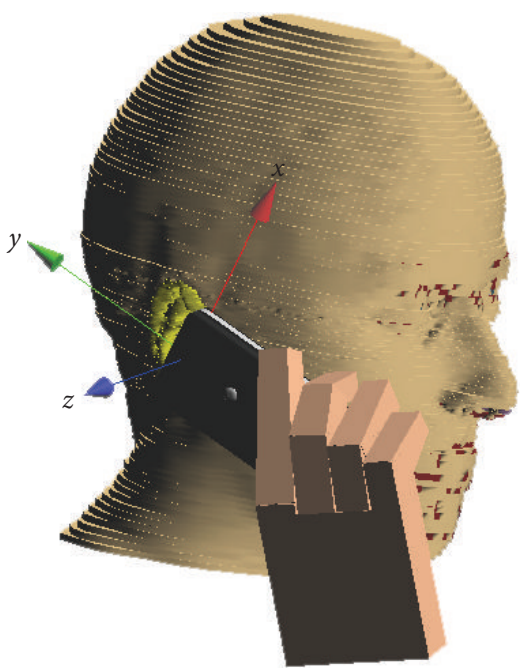

(c)

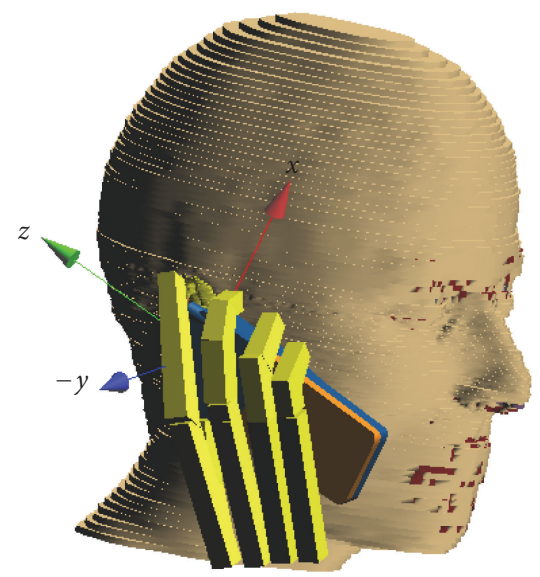

(b)

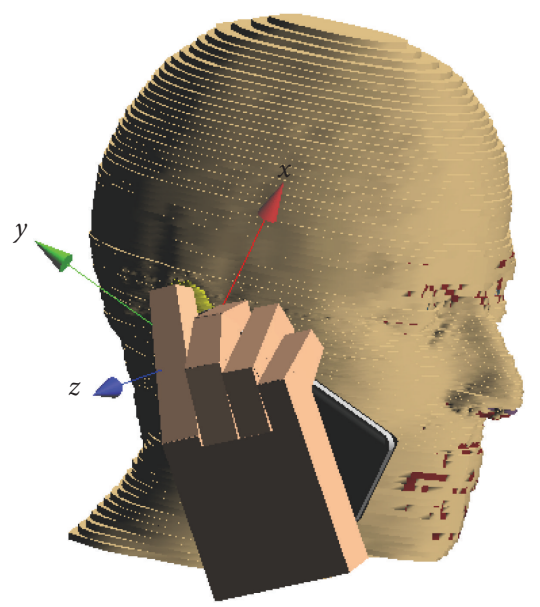

(d)

FIGURE 4: Different CAD representations of the handset in hand against HR-EFH at cheek position: (a) Model-A2 in hand1 (bone only), (b) Model-A1 in hand2 (bone only), (c) Model-B1 in hand1, and (d) Model-B1 in hand2.

as shown in Figure 11, internal antenna exhibits more variation in total efficiency values than external antenna. The maximum absolute difference $(25 \%)$ is recorded at $900 \mathrm{MHz}$ for model-B2 against HR-EFH at tilt position. The direction of arrows shown in Figure 11 indicates whether the total efficiency increases $(\uparrow)$ or decreases $(\downarrow)$ while shifting the hand from hand 1 to hand2. This arrow's indication is also applicable for the TIS and SAR in Figures 12 and 13, respectively.

(3) Although the interference of the external noisy components (i.e., display and camera, as well as their associated feed circuits) is not considered in simulation, the drop in TIS specification of handsets while in-use, as shown in Table 7, is caused by antenna total efficiency decrease due to hand impact. Simulating the handsets having external antennas, the maximum TIS level of $-94.9 \mathrm{dBm}$ is obtained for modelA1 in hand 2 against HR-EFH at cheek position operating at $1800 \mathrm{MHZ}$, where a minimum total efficiency of $7.6 \%$ is recorded, whereas simulating the handsets having internal antennas, the maximum TIS level of $-95.2 \mathrm{dBm}$ is obtained for model-B1 in hand2 against HR-EFH at cheek position operating at $2025 \mathrm{MHZ}$, where a minimum total efficiency of $8.5 \%$ is recorded. It is obvious that the maximum TIS level is around $10 \mathrm{~dB}$ higher for the above-mentioned handsets while in-use, as compared with them in free space.

(4) Figure 12 illustrates the absolute difference in TIS levels due to hand-hold alteration at different antenna/handset positions against the HR-EFH as depicted in Table 7. It is vivid that handsets with internal antennas exhibit more variation in their TIS levels than handsets with external antennas, where a maximum difference $(5.1 \mathrm{dBm})$ is recorded at $2025 \mathrm{MHz}$ for model-B1 at cheek position. A maximum difference $(5.1 \mathrm{dBm})$ is also recorded due to the hand-hold alteration at $900 \mathrm{MHz}$ for model-B1 just in hand.

(5) Figures 11 and 12 demonstrate that hand2 always has more impact on antenna performance including the TIS than 


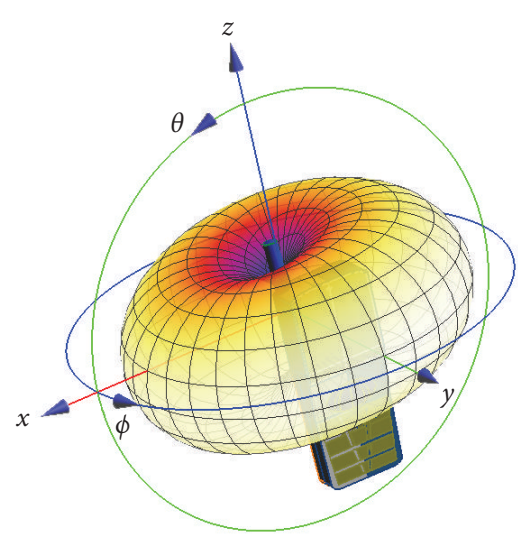

(a) Model-Al in free-space, $900 \mathrm{MHz}$

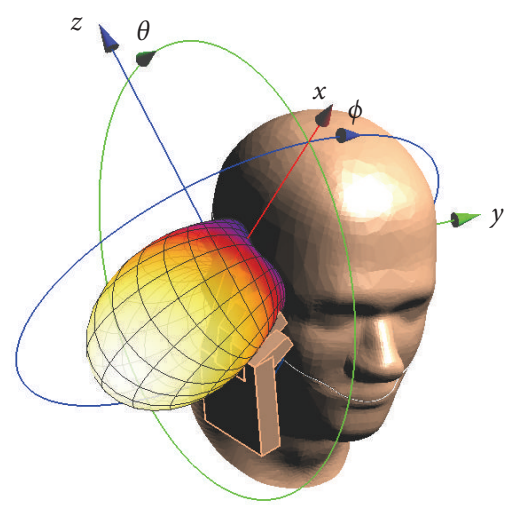

(d) Model-A1 in hand1 close to SAM, cheekposition, $900 \mathrm{MHz}$

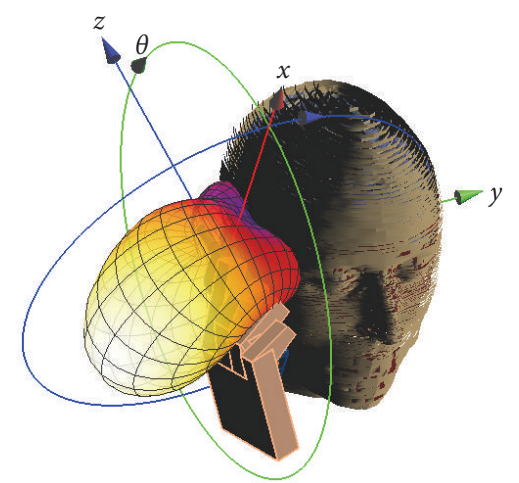

(g) Model-A1 in hand1 close to HR-EFH, cheek-position, $900 \mathrm{MHz}$

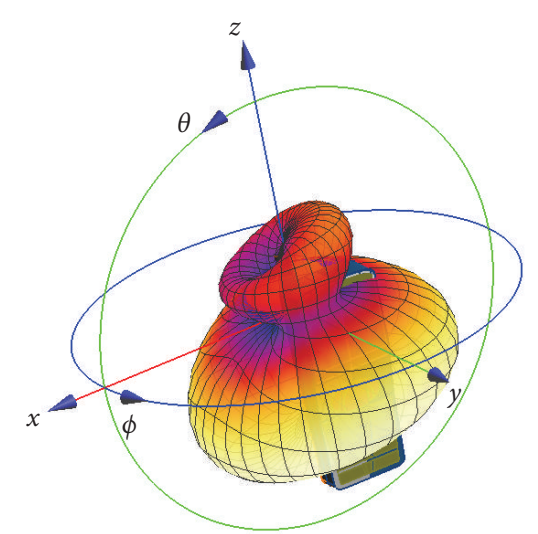

(b) Model-A1 in free-space, $1800 \mathrm{MHz}$

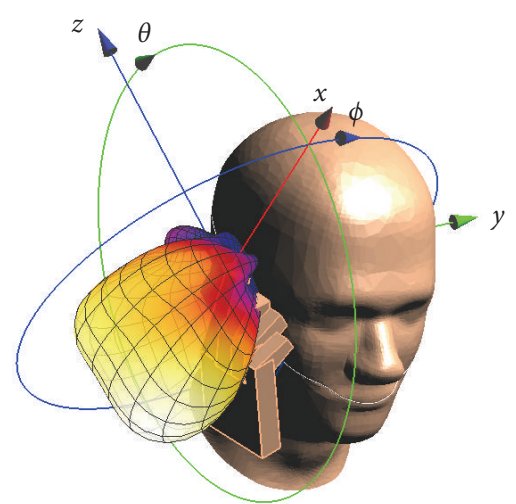

(e) Model-A1 in hand 1 close to SAM, cheekposition, $1800 \mathrm{MHz}$

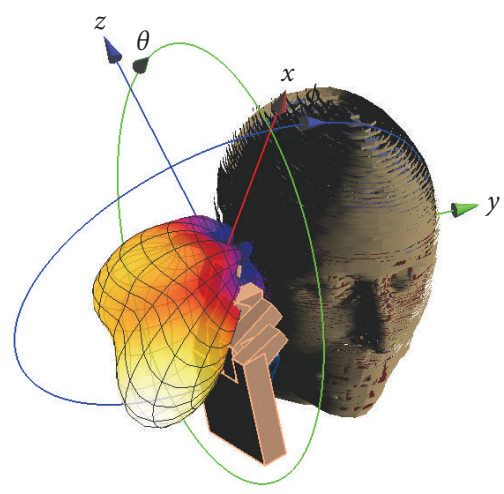

(h) Model-A1 in hand1 close to HR-EFH, cheek-position, $1800 \mathrm{MHz}$

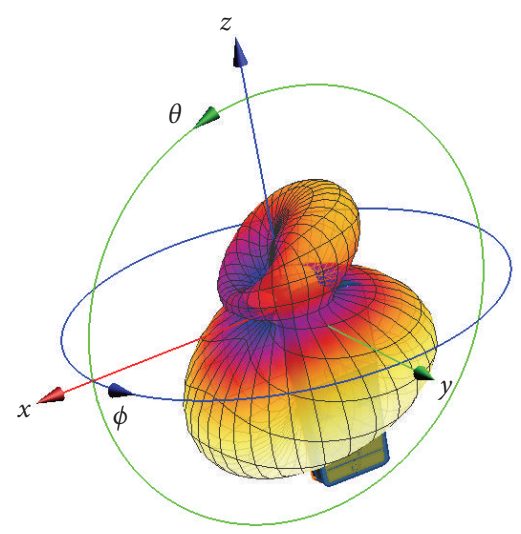

(c) Model-A1 in free-space, $2025 \mathrm{MHz}$

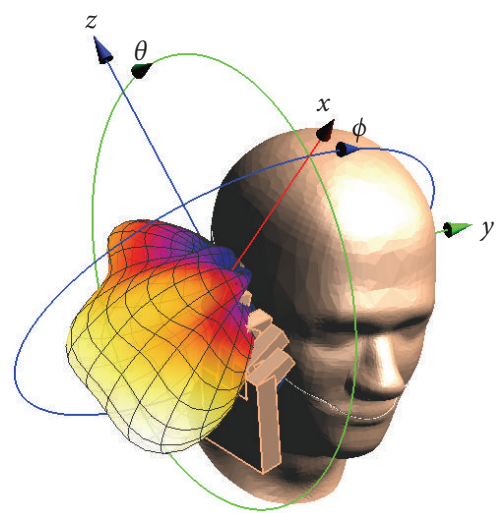

(f) Model-A1 in hand 1 close to SAM, cheekposition, $2025 \mathrm{MHz}$

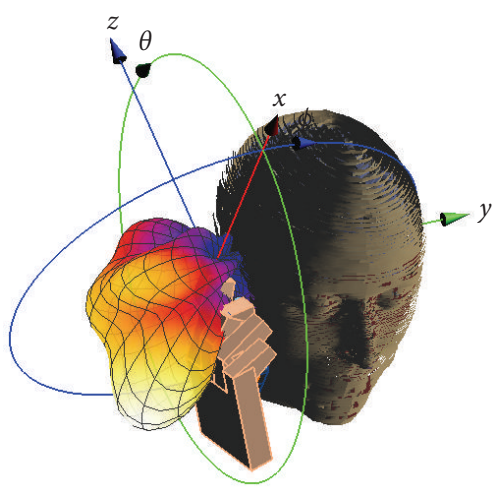

(i) Model-A1 in hand1 close to HR-EFH, cheek-position, $2025 \mathrm{MHz}$

FIGURE 5: The three-dimensional far-field radiation patterns of the handset model-A1 in free space, in hand1 close to SAM and in hand1 close to HR-EFH at 900, 1800, and $2025 \mathrm{MHz}$.

hand1, except for model-B2 against HR-EFH at cheek and tilt positions, while operating at $2025 \mathrm{MHz}$.

\subsection{SAR and power loss in tissues}

Tables 8-10 reveal that due to the exposure of the handset in hand close to HR-EFH at different positions and operat- ing frequencies, both the averaged-peak $\mathrm{SAR}_{1 \mathrm{~g}}$ and power absorption in tissues may vary considerably according to hand-hold position, observed as follows.

(1) More SAR variation in HR-EFH tissues is perceived owing to the internal antenna exposure, as compared with the external antenna exposure. Figure 13 shows the relation of the percentage of spatial-peak $S_{A R}$ difference values 


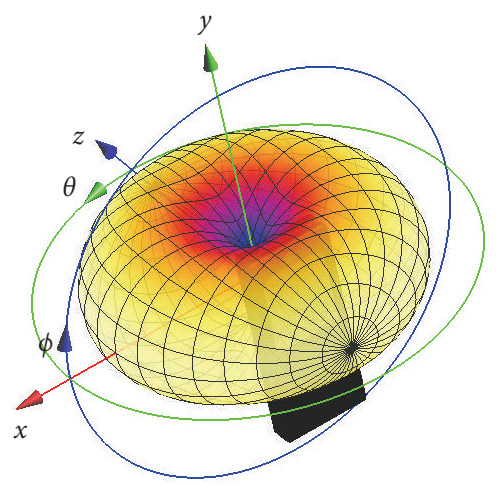

(a) Model-B1 in free-space, $900 \mathrm{MHz}$

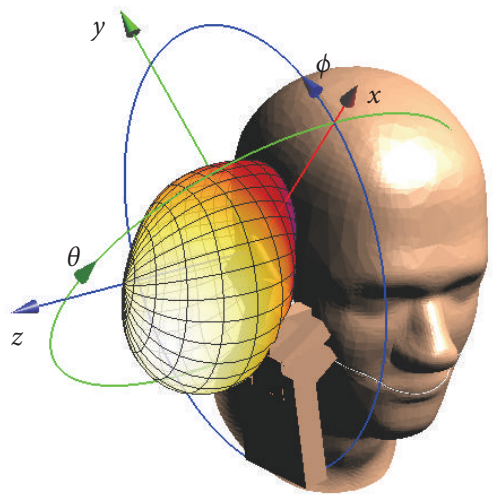

(d) Model-B1 in hand1 close to SAM, cheekposition, $900 \mathrm{MHz}$

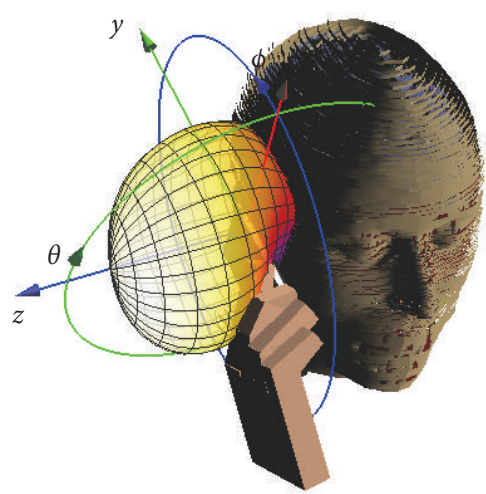

(g) Model-B1 in hand1 close to HR-EFH, cheek-position, $900 \mathrm{MHz}$

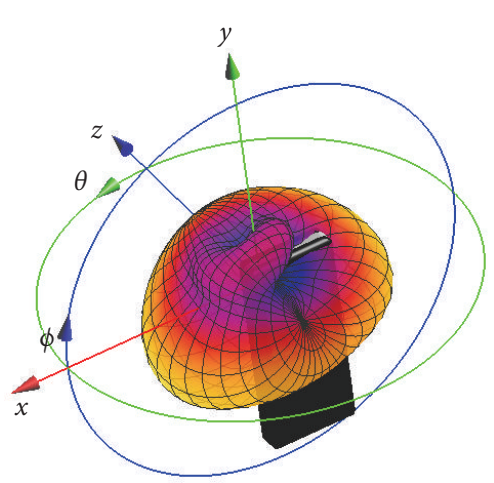

(b) Model-B1 in free-space, $1800 \mathrm{MHz}$

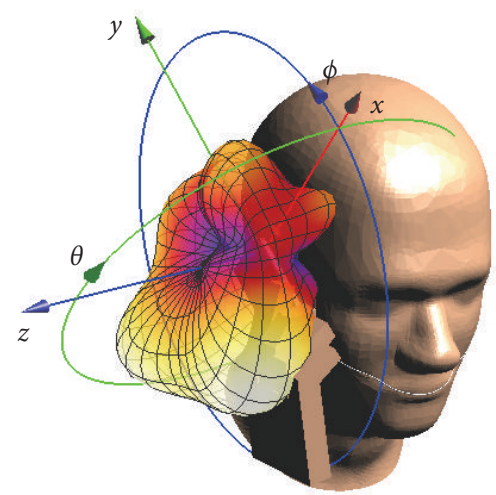

(e) Model-B1 in hand 1 close to SAM, cheekposition, $1800 \mathrm{MHz}$

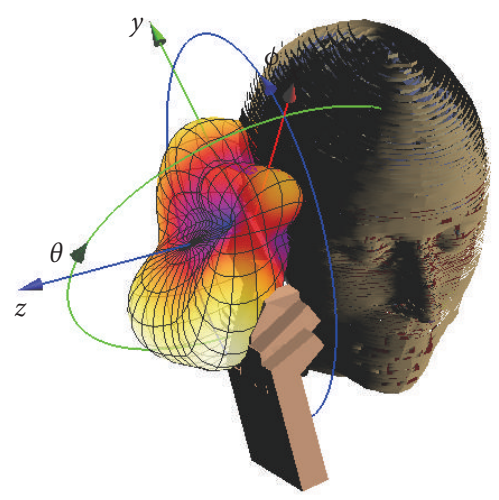

(h) Model-B1 in hand1 close to HR-EFH, cheek-position, $1800 \mathrm{MHz}$

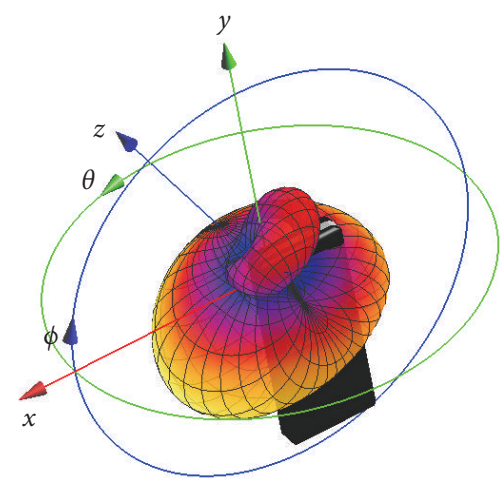

(c) Model-B1 in free-space, $2025 \mathrm{MHz}$

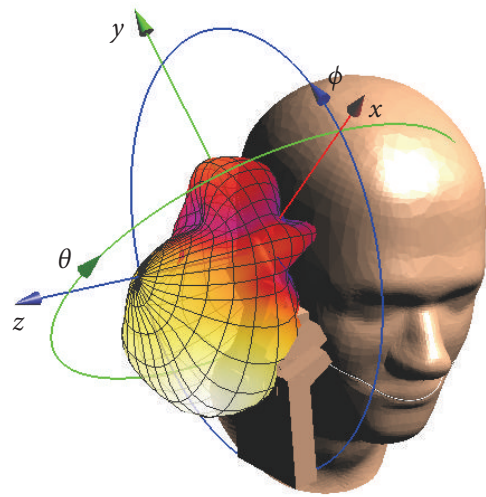

(f) Model-B1 in hand1 close to SAM, cheekposition, $2025 \mathrm{MHz}$

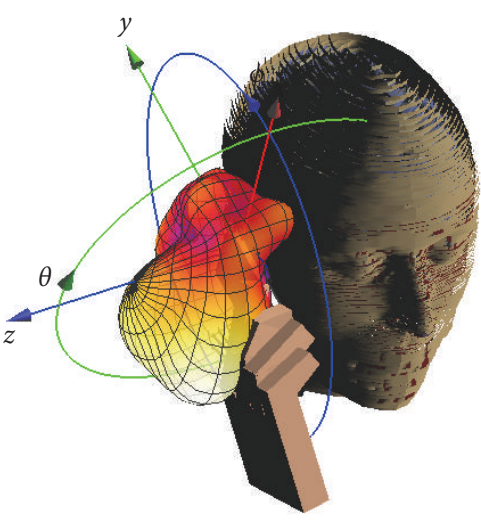

(i) Model-B1 in hand1 close to HR-EFH, cheek-position, $2025 \mathrm{MHz}$

FIgure 6: The three-dimensional far-field radiation beam patterns of the handset model-B1 in free space, in hand1 close to SAM and in hand 1 close to HR-EFH at 900, 1800, and $2025 \mathrm{MHz}$.

in HR-EFH tissues due to hand-hold alteration versus antenna/handset position at 900, 1800, and $2025 \mathrm{MHz}$. The percentage difference of SAR in HR-EFH tissues while shifting the hand from hand 1 to hand 2 is defined as

$\%$ Difference in SAR

$$
=\left(\frac{\text { SAR in HR-EFH with hand } 2}{\text { SAR in HR-EFH with hand1 }}-1\right) \times 100 \text {. }
$$

A maximum percentage difference in SAR $(86.8 \%)$ is recorded for model-B2 at cheek position and operating at $2025 \mathrm{MHz}$ (Figure 13(b)) which represents twice the maximum value of that recorded in cases of handsets having external antenna (Figure 13(a)).

(2) The direction of arrows shown in Figure 13(b) indicates that shifting of the hand-hold from hand 1 to hand2 may result in the decrease of spatial-peak $S_{A R}$ in HR-EFH tissues if exposed to model-B1 EM radiation at 
TABle 9: Pooled statistics of peak 1 and $10 \mathrm{~g}$ SAR in tissues, radiated power, absorbed power in tissues, dielectric loss, and power budget error for the handset models in hand closed to HR-EFH at different positions operating at $1800 \mathrm{MHz}$.

\begin{tabular}{|c|c|c|c|c|c|c|c|c|c|}
\hline \multirow{3}{*}{\multicolumn{2}{|c|}{$\begin{array}{l}\text { Handset model } \\
\text { Hand position } \\
\end{array}$}} & \multicolumn{8}{|c|}{ Frequency/1800 MHz } \\
\hline & & \multicolumn{2}{|c|}{ A1 } & \multicolumn{2}{|c|}{ A2 } & \multicolumn{2}{|c|}{$\mathrm{B} 1$} & \multicolumn{2}{|c|}{$\mathrm{B} 2$} \\
\hline & & hand1 & hand2 & hand1 & hand2 & hand1 & hand2 & hand1 & hand2 \\
\hline \multicolumn{2}{|c|}{ Antenna input power $(\mathrm{mW})$} & 125 & 125 & 125 & 125 & 125 & 125 & 125 & 125 \\
\hline \multirow{9}{*}{ Cheek-position } & $\mathrm{SAR}_{\lg }$ in head $(\mathrm{W} / \mathrm{kg})$ & 1.48 & 0.85 & 1.16 & 1.10 & 2.67 & 1.81 & 0.84 & 1.49 \\
\hline & $\mathrm{SAR}_{10 \mathrm{~g}}$ in head $(\mathrm{W} / \mathrm{kg})$ & 0.66 & 0.41 & 0.67 & 0.55 & 1.74 & 0.85 & 0.51 & 0.90 \\
\hline & $\mathrm{SAR}_{\mathrm{lg}}$ in hand $(\mathrm{W} / \mathrm{kg})$ & 1.28 & 3.87 & 1.21 & 2.01 & 0.84 & 1.82 & 1.65 & 1.06 \\
\hline & Radiated power $(\mathrm{mW})$ & 21.0 & 9.55 & 36.2 & 24.2 & 27.9 & 15.3 & 26.9 & 17.3 \\
\hline & Absorbed power in head (mW) & 53.7 & 36.2 & 45.7 & 38.9 & 61.7 & 44.6 & 27.8 & 47.7 \\
\hline & Absorption rate in head $(\%)$ & 43.0 & 29.0 & 36.6 & 31.2 & 49.4 & 35.7 & 22.3 & 38.2 \\
\hline & Absorbed power in hand (mW) & 36.6 & 63.9 & 31.1 & 50.0 & 24.3 & 58.2 & 60.8 & 47.0 \\
\hline & Dielectric loss $(\mathrm{mW})$ & 13.4 & 12.8 & 11.8 & 11.4 & 10.9 & 5.30 & 9.30 & 12.3 \\
\hline & Power budget error (\%) & 0.18 & 2.00 & 0.16 & 0.33 & 0.10 & 1.27 & 0.12 & 0.58 \\
\hline \multirow{9}{*}{ Tilt-position } & $\mathrm{SAR}_{1 \mathrm{~g}}$ in head $(\mathrm{W} / \mathrm{kg})$ & 1.54 & 0.89 & 0.93 & 1.06 & 2.46 & 1.66 & 0.42 & 0.77 \\
\hline & $\mathrm{SAR}_{10 \mathrm{~g}}$ in head $(\mathrm{W} / \mathrm{kg})$ & 0.60 & 0.35 & 0.53 & 0.49 & 1.10 & 0.72 & 0.26 & 0.45 \\
\hline & $\mathrm{SAR}_{\mathrm{lg}}$ in hand $(\mathrm{W} / \mathrm{kg})$ & 1.25 & 3.80 & 1.60 & 2.24 & 1.12 & 2.17 & 1.94 & 1.36 \\
\hline & Radiated power $(\mathrm{mW})$ & 23.6 & 11.0 & 35.7 & 22.9 & 29.2 & 18.3 & 31.3 & 27.2 \\
\hline & Absorbed power in head (mW) & 50.5 & 35.7 & 42.4 & 36.1 & 52.2 & 37.9 & 17.4 & 26.8 \\
\hline & Absorption rate in head $(\%)$ & 40.4 & 28.6 & 34.0 & 28.9 & 41.8 & 30.4 & 13.9 & 21.4 \\
\hline & Absorbed power in hand (mW) & 37.0 & 63.1 & 34.2 & 53.6 & 29.7 & 60.3 & 65.1 & 58.0 \\
\hline & Dielectric loss $(\mathrm{mW})$ & 13.2 & 12.7 & 12.0 & 11.4 & 13.6 & 6.46 & 10.6 & 12.8 \\
\hline & Power budget error (\%) & 0.44 & 1.96 & 0.54 & 0.74 & 0.21 & 1.62 & 0.45 & 0.17 \\
\hline
\end{tabular}

TABLE 10: Pooled statistics of peak 1 and $10 \mathrm{~g}$ SAR in tissues, radiated power, absorbed power in tissues, dielectric loss, and power budget error for the handset models in hand closed to HR-EFH at different positions operating at $2025 \mathrm{MHz}$.

\begin{tabular}{|c|c|c|c|c|c|c|c|c|c|}
\hline \multirow{3}{*}{\multicolumn{2}{|c|}{$\begin{array}{l}\text { Handset model } \\
\text { Hand position }\end{array}$}} & \multicolumn{8}{|c|}{ Frequency/2025 MHz } \\
\hline & & \multicolumn{2}{|c|}{ A1 } & \multicolumn{2}{|c|}{$\mathrm{A} 2$} & \multicolumn{2}{|c|}{$\mathrm{B} 1$} & \multicolumn{2}{|c|}{ B2 } \\
\hline & & hand1 & hand2 & hand1 & hand2 & hand1 & hand2 & hand1 & hand2 \\
\hline \multicolumn{2}{|c|}{ Antenna input power (mW) } & 125 & 125 & 125 & 125 & 125 & 125 & 125 & 125 \\
\hline \multirow{9}{*}{ Cheek-position } & $\mathrm{SAR}_{\mathrm{lg}}$ in head $(\mathrm{W} / \mathrm{kg})$ & 1.85 & 1.09 & 1.39 & 1.64 & 3.78 & 2.40 & 0.71 & 1.32 \\
\hline & $\mathrm{SAR}_{10 \mathrm{~g}}$ in head $(\mathrm{W} / \mathrm{kg})$ & 0.77 & 0.50 & 0.77 & 0.78 & 1.70 & 1.15 & 0.43 & 0.80 \\
\hline & $\mathrm{SAR}_{\mathrm{lg}}$ in hand $(\mathrm{W} / \mathrm{kg})$ & 2.12 & 4.10 & 1.98 & 1.95 & 0.58 & 2.10 & 1.83 & 2.17 \\
\hline & Radiated power $(\mathrm{mW})$ & 23.0 & 11.3 & 39.3 & 22.9 & 33.4 & 10.6 & 18.3 & 19.2 \\
\hline & Absorbed power in head (mW) & 53.7 & 36.7 & 44.8 & 43.7 & 68.6 & 49.4 & 26.0 & 44.0 \\
\hline & Absorption rate in head (\%) & 43.0 & 29.3 & 35.8 & 35.0 & 54.9 & 39.5 & 20.8 & 35.2 \\
\hline & Absorbed power in hand (mW) & 36.7 & 64.4 & 30.0 & 47.3 & 14.5 & 59.3 & 68.0 & 51.0 \\
\hline & Dielectric loss $(\mathrm{mW})$ & 11.0 & 10.0 & 10.7 & 10.8 & 8.00 & 3.10 & 10.4 & 10.0 \\
\hline & Power budget error (\%) & 0.48 & 2.00 & 0.14 & 0.12 & 0.36 & 2.06 & 1.86 & 0.62 \\
\hline \multirow{9}{*}{ Tilt-position } & $\mathrm{SAR}_{\mathrm{lg}}$ in head $(\mathrm{W} / \mathrm{kg})$ & 1.91 & 1.15 & 1.17 & 1.58 & 3.80 & 2.20 & 0.38 & 0.71 \\
\hline & $\mathrm{SAR}_{10 \mathrm{~g}}$ in head $(\mathrm{W} / \mathrm{kg})$ & 0.67 & 0.42 & 0.60 & 0.69 & 1.54 & 0.93 & 0.23 & 0.40 \\
\hline & $\mathrm{SAR}_{\lg }$ in hand $(\mathrm{W} / \mathrm{kg})$ & 2.17 & 4.18 & 2.31 & 1.98 & 0.92 & 2.16 & 2.10 & 2.72 \\
\hline & Radiated power $(\mathrm{mW})$ & 26.4 & 12.6 & 40.6 & 24.2 & 35.6 & 12.9 & 23.1 & 29.0 \\
\hline & Absorbed power in head (mW) & 50.7 & 35.0 & 40.8 & 40.1 & 59.0 & 43.2 & 17.6 & 26.2 \\
\hline & Absorption rate in head (\%) & 40.6 & 28.0 & 32.6 & 32.0 & 47.2 & 34.6 & 14.1 & 21.0 \\
\hline & Absorbed power in hand (mW) & 36.8 & 64.9 & 32.9 & 50.1 & 22.0 & 62.7 & 71.5 & 58.0 \\
\hline & Dielectric loss $(\mathrm{mW})$ & 10.8 & 9.8 & 9.8 & 10.2 & 8.2 & 3.6 & 10.6 & 9.8 \\
\hline & Power budget error (\%) & 0.18 & 2.12 & 0.7 & 0.38 & 0.13 & 2.06 & 1.78 & 1.60 \\
\hline
\end{tabular}




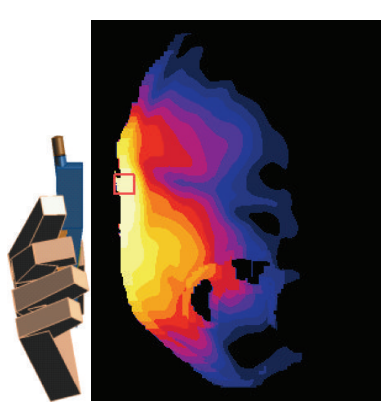

Peak at $x=13.25 \mathrm{~mm}$ $900 \mathrm{MHz}$, hand1, cheek $0 \mathrm{~dB}=3.38 \mathrm{~W} / \mathrm{kg}$

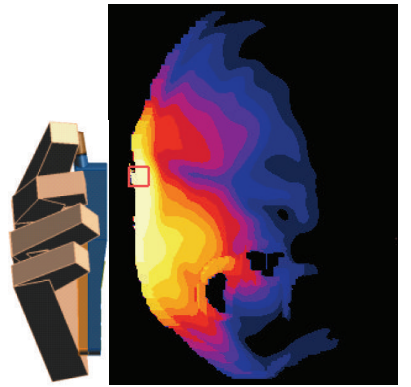

Peak at $x=13.25 \mathrm{~mm}$ $900 \mathrm{MHz}$, hand2, cheek $0 \mathrm{~dB}=2.52 \mathrm{~W} / \mathrm{kg}$

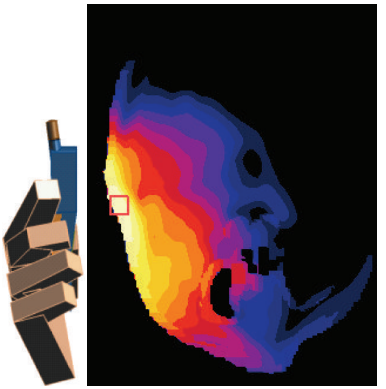

Peak at $x=14.75 \mathrm{~mm}$ $900 \mathrm{MHz}$, hand1, tilt $0 \mathrm{~dB}=2.61 \mathrm{~W} / \mathrm{kg}$

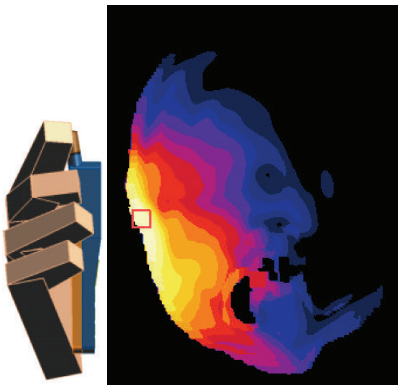

Peak at $x=14.25 \mathrm{~mm}$ $900 \mathrm{MHz}$, hand2, tilt $0 \mathrm{~dB}=1.99 \mathrm{~W} / \mathrm{kg}$

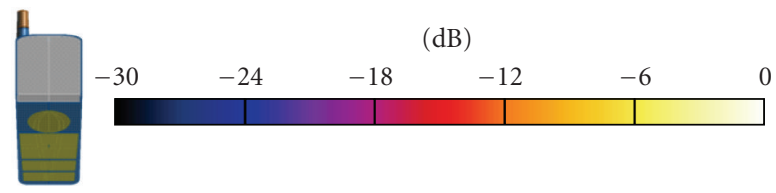

(a)

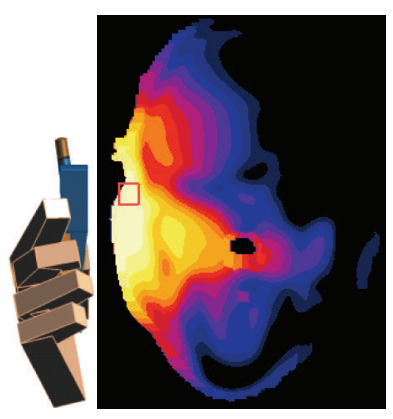

Peak at $x=-5.41 \mathrm{~mm}$ $900 \mathrm{MHz}$, hand1, cheek $0 \mathrm{~dB}=2.77 \mathrm{~W} / \mathrm{kg}$

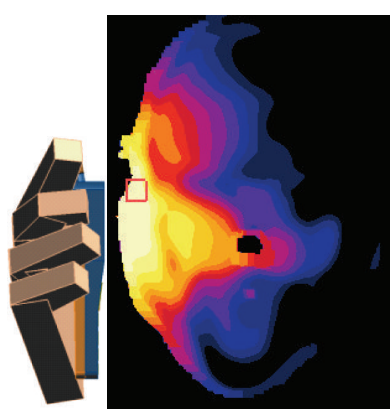

Peak at $x=-5.41 \mathrm{~mm}$ $900 \mathrm{MHz}$, hand2, cheek $0 \mathrm{~dB}=2.51 \mathrm{~W} / \mathrm{kg}$

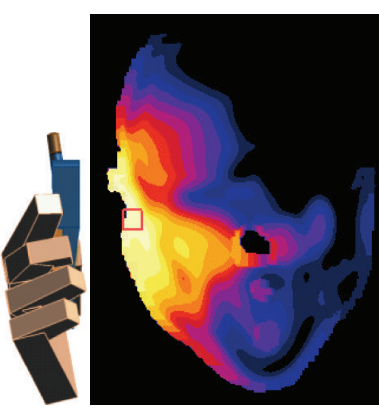

Peak at $x=-5.71 \mathrm{~mm}$ $900 \mathrm{MHz}$, hand1, tilt $0 \mathrm{~dB}=2.04 \mathrm{~W} / \mathrm{kg}$

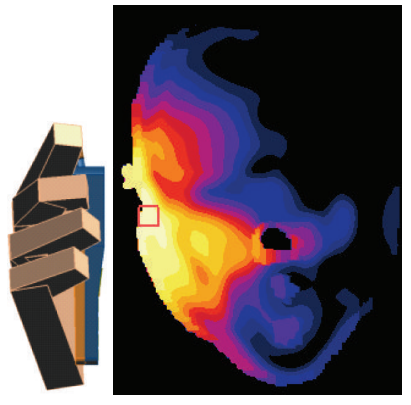

Peak at $x=-4.95 \mathrm{~mm}$ $900 \mathrm{MHz}$, hand2, tilt $0 \mathrm{~dB}=1.9 \mathrm{~W} / \mathrm{kg}$

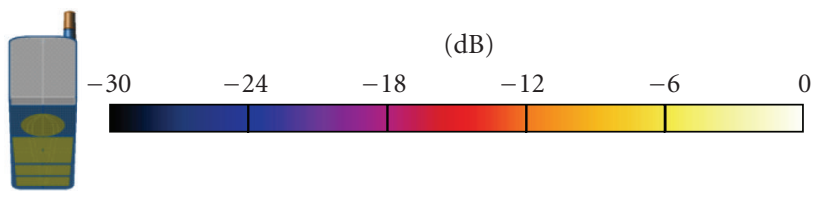

(b)

FIGURE 7: Sliced distribution of the averaged-peak $\mathrm{SAR}_{1 \mathrm{~g}}$ in the $y z$-plane, normalized to $0.6 \mathrm{~W}$ input power, of the HR-EFH at different positions due to the exposure at $900 \mathrm{MHz}$ of (a) handset model-A1 and (b) handset model-A2.

different positions and frequencies, whereas the same shift may increase the spatial-peak $\mathrm{SAR}_{1 \mathrm{~g}}$ when exposed to modelB2. This SAR behavior due to the hand-hold shifting is also applicable when the head exposes to the EM radiation of handset models-A1 and A2, respectively, (Figure 13(a)) but with minor difference in some exceptional cases with modelA2. It is because of the antenna is located on top of the handset and the distance between its feeding position and the nearest head tissue being almost the same while using both model-A1 and model-A2.

(3) In [12], shifting the hand-hold from the lower part of the chassis (hand position $=60 \mathrm{~mm}$ ) to the upper part (hand position $=0 \mathrm{~mm}$ ), which is to some extent the same hand-hold alteration proposed in this study, the spatialpeak $\mathrm{SAR}_{1 \mathrm{~g}}$ in head got decreased from $6 \mathrm{~W} / \mathrm{kg}$ to $4 \mathrm{~W} / \mathrm{kg}$ at $900 \mathrm{MHz}$, and from $5.5 \mathrm{~W} / \mathrm{kg}$ to $3.5 \mathrm{~W} / \mathrm{kg}$ at $1800 \mathrm{MHz}$. The corresponding percentage differences in SAR (8) are $-33.3 \%$ and $-36.3 \%$, respectively. Although different hand/handset models used in this study, as compared with those in [12], the above percentage differences in SAR values nearly coincide with the results drawn in Figure 13(b) for model-B1 at cheek and tilt positions operating at 900 and $1800 \mathrm{MHz}$. Relative to the head, the chase in [12] was tilted $\left(74^{\circ}\right)$ from the vertical and $\left(10^{\circ}\right)$ from the ear toward the cheek. 


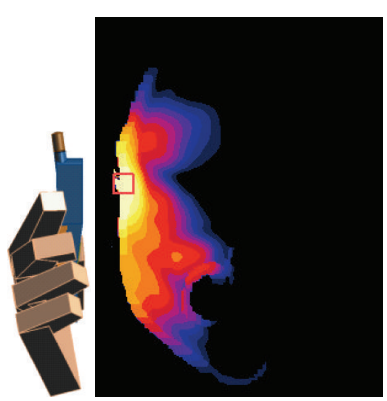

Peak at $x=13.11 \mathrm{~mm}$ $1800 \mathrm{MHz}$, hand 1 , cheek $0 \mathrm{~dB}=1.48 \mathrm{~W} / \mathrm{kg}$

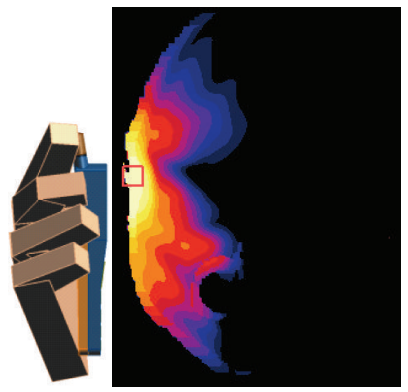

Peak at $x=13.11 \mathrm{~mm}$ $1800 \mathrm{MHz}$, hand2, cheek $0 \mathrm{~dB}=0.85 \mathrm{~W} / \mathrm{kg}$

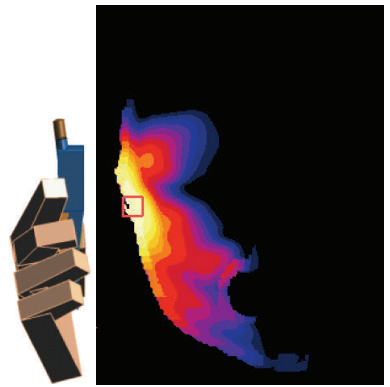

Peak at $x=12.2 \mathrm{~mm}$ $1800 \mathrm{MHz}$, hand1, tilt $0 \mathrm{~dB}=1.54 \mathrm{~W} / \mathrm{kg}$

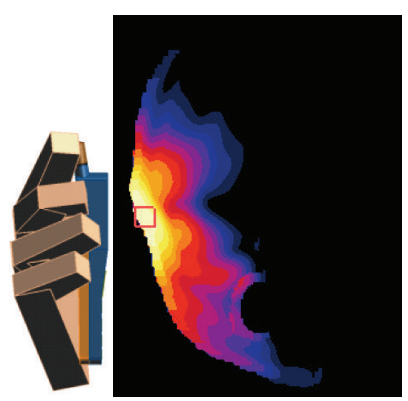

Peak at $x=14.75 \mathrm{~mm}$ $1800 \mathrm{MHz}$, hand2, tilt $0 \mathrm{~dB}=0.89 \mathrm{~W} / \mathrm{kg}$

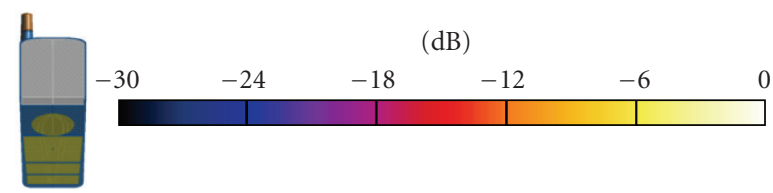

(a)

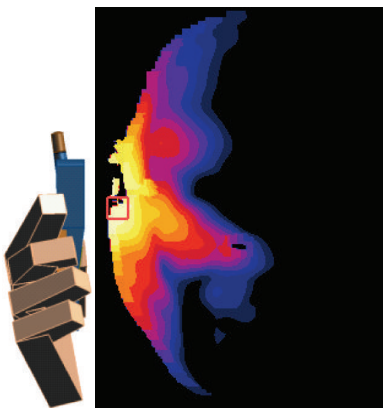

Peak at $x=-13.11 \mathrm{~mm}$ $1800 \mathrm{MHz}$, hand1, cheek $0 \mathrm{~dB}=1.16 \mathrm{~W} / \mathrm{kg}$

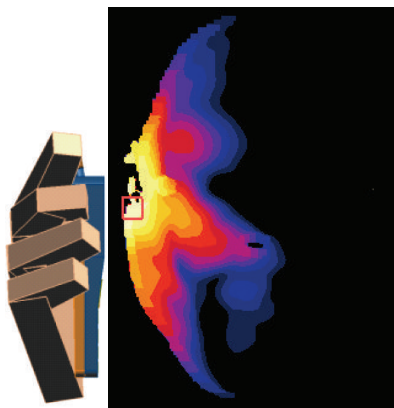

Peak at $x=-13.75 \mathrm{~mm}$ $1800 \mathrm{MHz}$, hand2, cheek $0 \mathrm{~dB}=1.1 \mathrm{~W} / \mathrm{kg}$

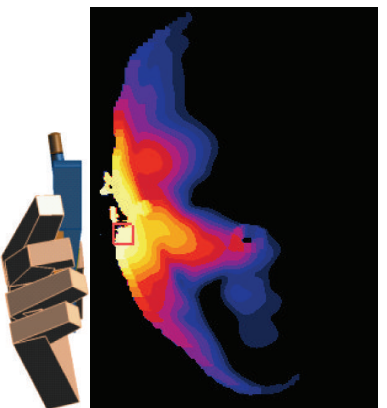

Peak at $x=-13.75 \mathrm{~mm}$ $1800 \mathrm{MHz}$, hand1, tilt $0 \mathrm{~dB}=0.93 \mathrm{~W} / \mathrm{kg}$

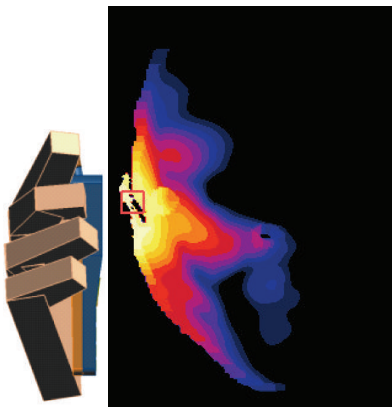

Peak at $x=-16.75 \mathrm{~mm}$ $1800 \mathrm{MHz}$, hand2, tilt $0 \mathrm{~dB}=1.06 \mathrm{~W} / \mathrm{kg}$

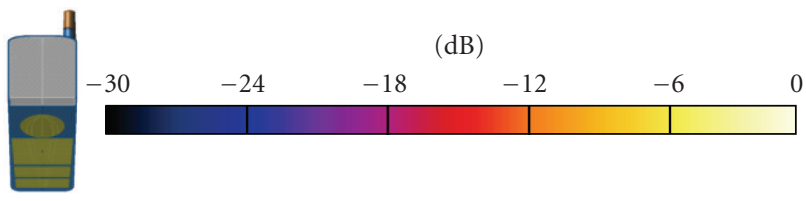

(b)

FIGURE 8: Sliced distribution of the averaged-peak $\mathrm{SAR}_{\lg }$ in the $y z$-plane, normalized to $0.125 \mathrm{~W}$ input power, of the HR-EFH at different positions due to the exposure at $1800 \mathrm{MHz}$ of (a) handset model-A1 and (b) handset model-A2.

(4) It is clear from Figure 13 that the operating frequency has a considerable effect on the SAR values in head tissues while shifting the hand-hold with different handset position and different antenna types/positions. Moreover, the considerable effect of the frequency change is also noticed in both antenna total efficiency and TIS shown in Figures 11 and 12 , respectively, where this effect appears stronger in cases of internal antennas than cases of external antennas.

(5) The percentage values of power absorption in head (SAM and HR-EFH) at different antenna/handset positions in GSM900, GSM1800, and UMTS/IMT-2000 bands are narrated and illustrated in Figure 14. The percentage power absorption is given by

\% Power absorption in tissue

$$
=\frac{\text { Power absorption in tissue }(\mathrm{W})}{\text { Antenna input power }(\mathrm{W})} \times 100 \text {. }
$$

Both SAM and HR-EFH absorb more power with hand1 than with hand2, when exposed to the EM radiation of handset with external antenna in different conditions. This 


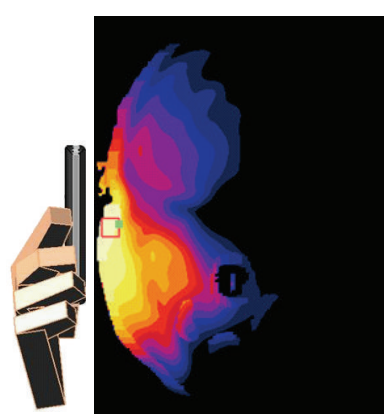

Peak at $x=11.46 \mathrm{~mm}$ $900 \mathrm{MHz}$, hand1, cheek $0 \mathrm{~dB}=4.87 \mathrm{~W} / \mathrm{kg}$

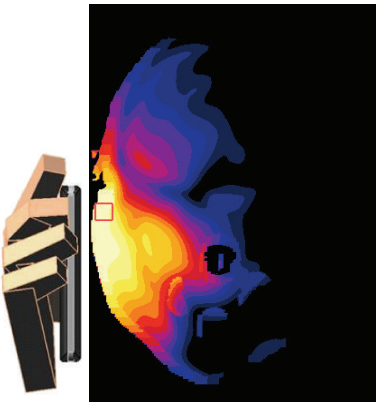

Peak at $x=11.46 \mathrm{~mm}$ $900 \mathrm{MHz}$, hand2, cheek $0 \mathrm{~dB}=3.23 \mathrm{~W} / \mathrm{kg}$

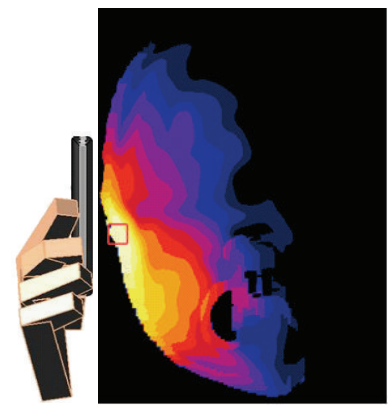

Peak at $x=16.63 \mathrm{~mm}$ $900 \mathrm{MHz}$, hand1, tilt $0 \mathrm{~dB}=3.19 \mathrm{~W} / \mathrm{kg}$

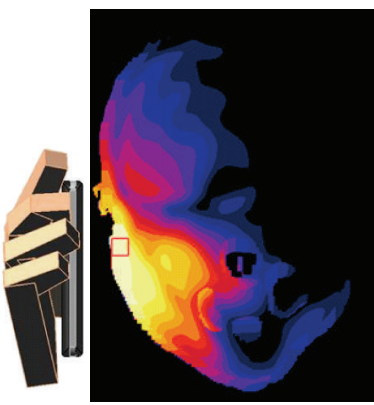

Peak at $x=19.46 \mathrm{~mm}$ $900 \mathrm{MHz}$, hand2, tilt $0 \mathrm{~dB}=2.04 \mathrm{~W} / \mathrm{kg}$

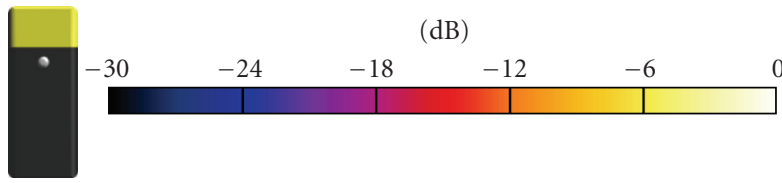

(a)

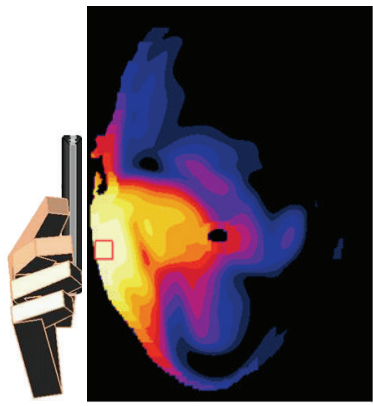

Peak at $x=-4.32 \mathrm{~mm}$ $900 \mathrm{MHz}$, hand 1 , cheek $0 \mathrm{~dB}=2.21 \mathrm{~W} / \mathrm{kg}$

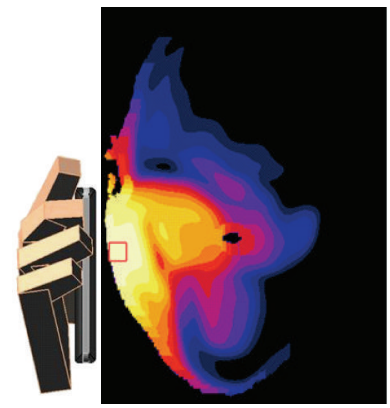

Peak at $x=-4.97 \mathrm{~mm}$ $900 \mathrm{MHz}$, hand2, cheek $0 \mathrm{~dB}=3.07 \mathrm{~W} / \mathrm{kg}$

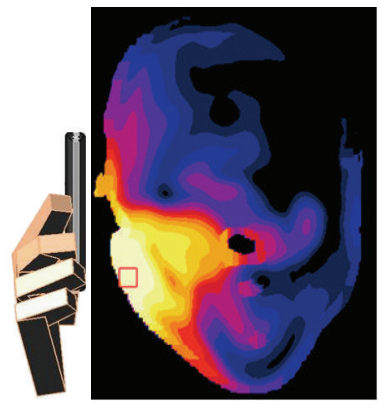

Peak at $x=-5.1 \mathrm{~mm}$ $900 \mathrm{MHz}$, hand1, tilt $0 \mathrm{~dB}=0.91 \mathrm{~W} / \mathrm{kg}$

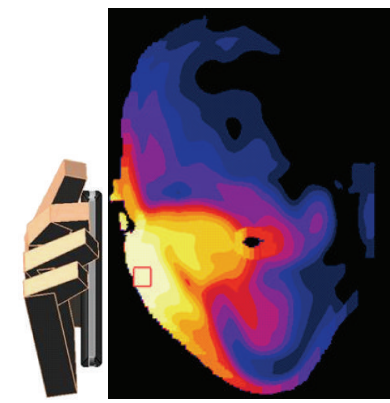

Peak at $x=-5.97 \mathrm{~mm}$ $900 \mathrm{MHz}$, hand2, tilt $0 \mathrm{~dB}=1.52 \mathrm{~W} / \mathrm{kg}$

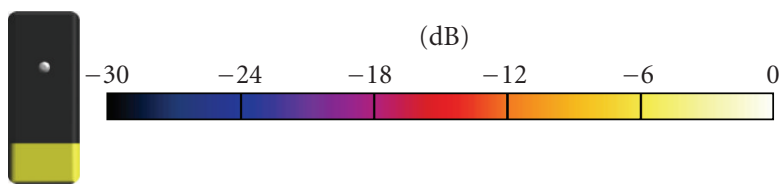

(b)

FIGURE 9: Sliced distribution of the averaged-peak $\mathrm{SAR}_{1 \mathrm{~g}}$ in the $y z$-plane, normalized to $0.6 \mathrm{~W}$ input power, of the HR-EFH at different positions due to the exposure at $900 \mathrm{MHz}$ of (a) handset model-B1 and (b) handset model-B2.

is also true when the head was exposed to the EM radiation of the handset with internal antenna model-B1, whereas with model-B2, head-tissues absorb less power with hand1 than with hand2. It is because both antenna and its feeding positions are at the upper part of the models-A1, A2, and $\mathrm{B} 1$, and shifting the hand from hand 1 to hand 2 will cover the antenna, whereas both antenna and its feeding positions are at the lower part of model-B2 and shifting the hand from hand 1 to hand 2 will uncover the patch antenna. Covering the antenna by user's hand may increase the power absorption in hand tissues and decrease it in head tissues.
(6) To some context, the power absorption in hand tissues behaves inversely to that in head.

\subsection{Power loss in handset materials}

The power loss in handset materials is corresponded to the dielectric loss (since all the metal parts are considered as PEC in simulations and consequently the metallic ohmicloss equal to zero). Tables $8-10$ give the dielectric loss values for the twelve handset models in different usage patterns. Although both handset models with internal and 


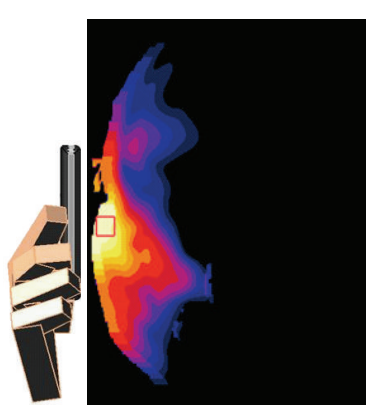

Peak at $x=10.8 \mathrm{~mm}$ $1800 \mathrm{MHz}$, hand1, cheek $0 \mathrm{~dB}=2.67 \mathrm{~W} / \mathrm{kg}$

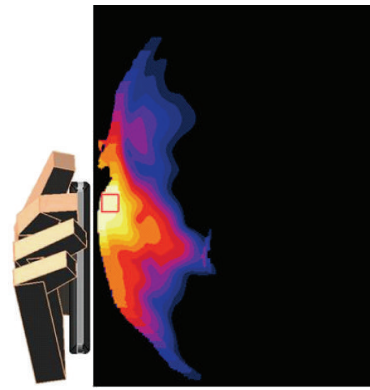

Peak at $x=9.5 \mathrm{~mm}$ $1800 \mathrm{MHz}$, hand2, cheek $0 \mathrm{~dB}=1.81 \mathrm{~W} / \mathrm{kg}$

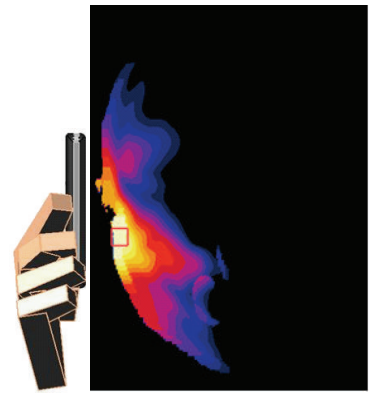

Peak at $x=8.06 \mathrm{~mm}$ $1800 \mathrm{MHz}$, hand1, tilt $0 \mathrm{~dB}=2.46 \mathrm{~W} / \mathrm{kg}$

(dB)

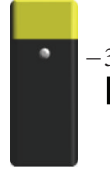

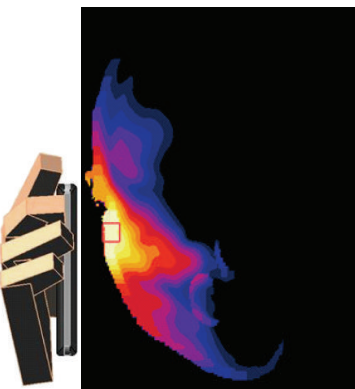

Peak at $x=8.06 \mathrm{~mm}$ $1800 \mathrm{MHz}$, hand2, tilt $0 \mathrm{~dB}=1.66 \mathrm{~W} / \mathrm{kg}$

(a)

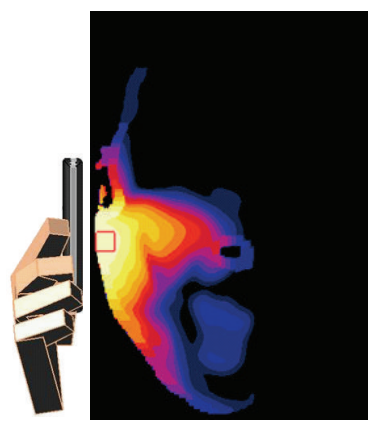

Peak at $x=-4.16 \mathrm{~mm}$ $1800 \mathrm{MHz}$, hand1, cheek $0 \mathrm{~dB}=0.84 \mathrm{~W} / \mathrm{kg}$

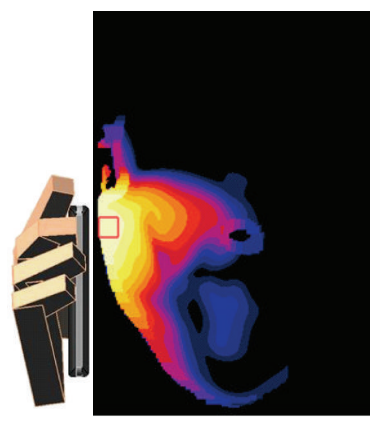

Peak at $x=-4.59 \mathrm{~mm}$ $1800 \mathrm{MHz}$, hand2, cheek $0 \mathrm{~dB}=1.49 \mathrm{~W} / \mathrm{kg}$

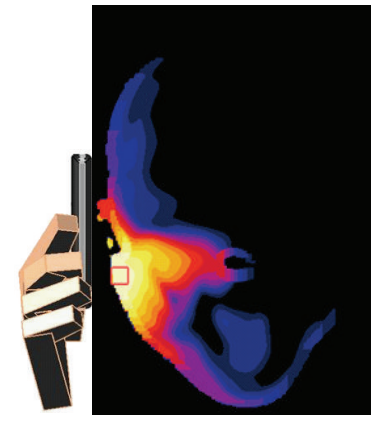

Peak at $x=-3.68 \mathrm{~mm}$ $1800 \mathrm{MHz}$, hand1, tilt $0 \mathrm{~dB}=0.42 \mathrm{~W} / \mathrm{kg}$

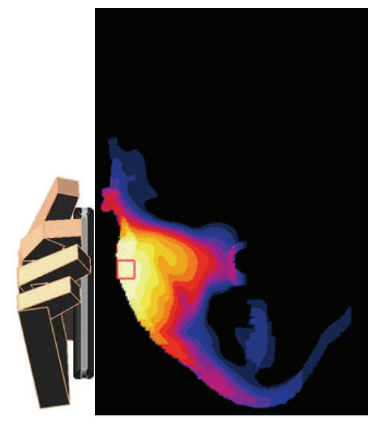

Peak at $x=-4.16 \mathrm{~mm}$ $1800 \mathrm{MHz}$, hand2, tilt $0 \mathrm{~dB}=0.77 \mathrm{~W} / \mathrm{kg}$

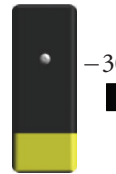

(dB)

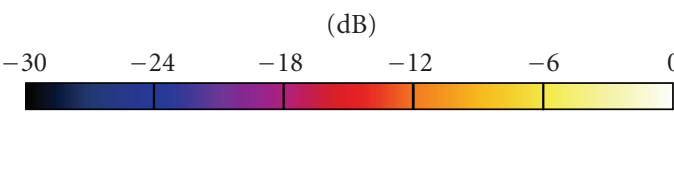

(b)

FIGURE 10: Sliced distribution of the averaged-peak $\mathrm{SAR}_{1 \mathrm{~g}}$ in the $y z$-plane, normalized to $0.125 \mathrm{~W}$ input power, of the HR-EFH at different positions due to the exposure at $1800 \mathrm{MHz}$ of (a) handset model-B1 and (b) handset model-B2.

external antennas use the same material properties for their components and parts, they have different volumes of dielectric materials and consequently different amounts of dielectric loss. However, it is obvious that the handhold alteration has a significant effect on the dielectric loss amount of the handsets having internal antennas, as compared with the handsets having external antennas; it is because of their different antenna types and positions. The percentage difference in the dielectric loss values owing to hand-hold alteration can be defined as
\% Difference in $P_{d}=\left(\frac{P_{d} \text { with hand2 }}{P_{d} \text { with hand1 }}-1\right) \times 100$.

The dielectric loss of the handset with internal antenna gets decreased while shifting the hand from hand1 to hand2, where a maximum percentage difference of $-68.8 \%$ is recorded at $900 \mathrm{MHz}$ for model-B1 at cheek position, whereas no more than $-11.4 \%$ is recorded for model-A 1 at the same frequency and position. The negative sign of the percentage values indicates that hand 2 has more impact than hand 1 . 


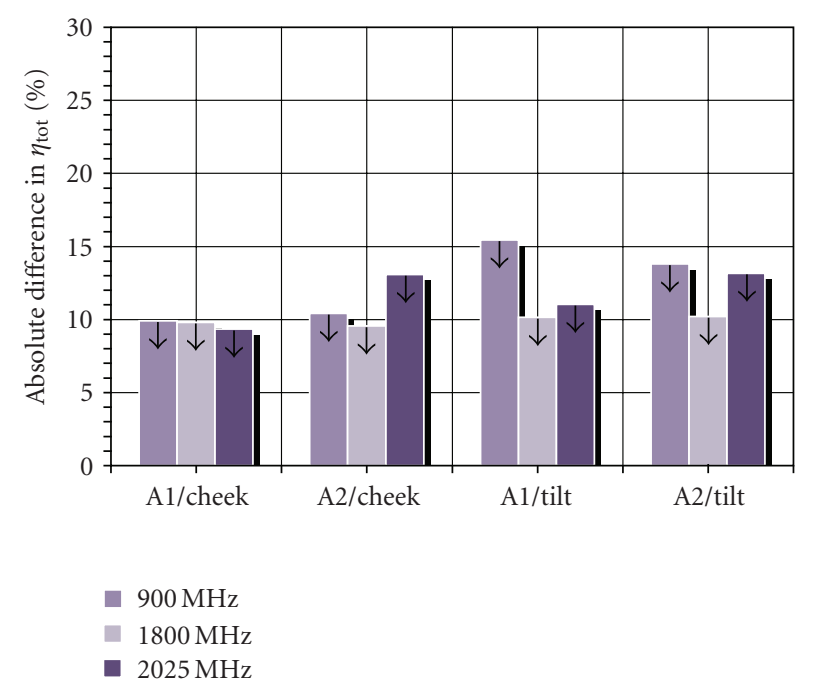

(a) Models-A1 and A2 against HR-EFH

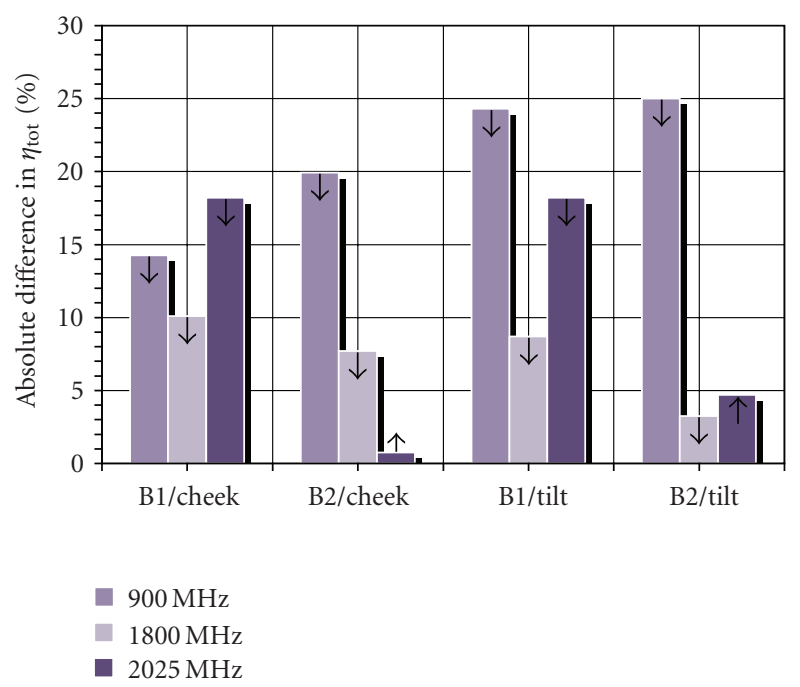

(b) Models-B1 and B2 against HR-EFH

FIGURE 11: Absolute difference in the antenna total efficiency owing to hand-hold alteration at different antenna/handset positions against HR-EFH in GSM900, GSM1800, and UMTS/IMT-2000 bands.

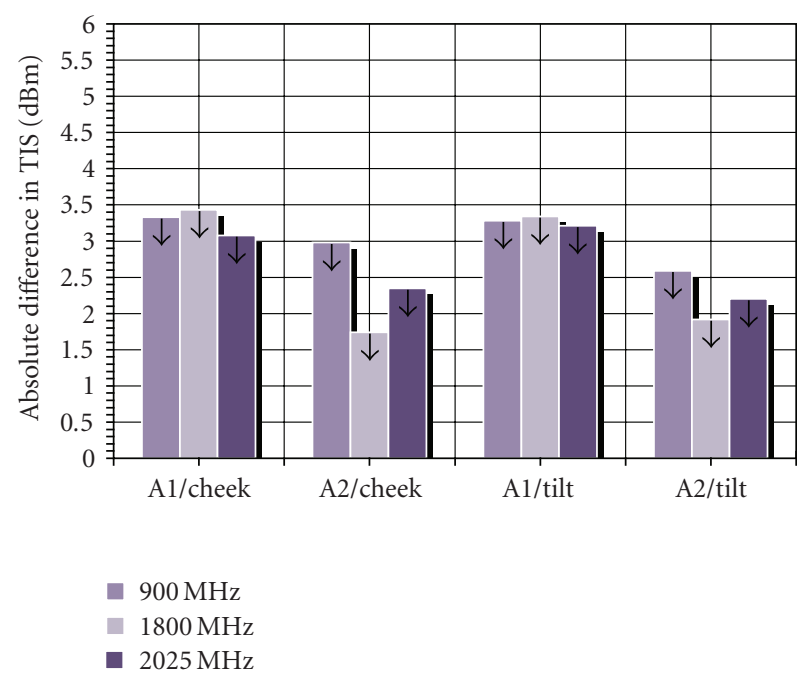

(a) Models-A1 and A2 against HR-EFH

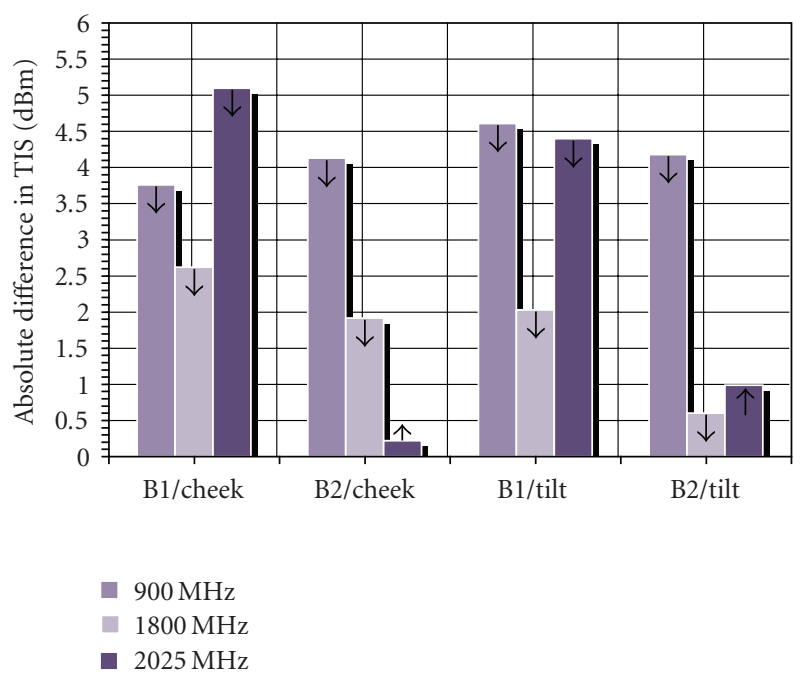

(b) Models-B1 and B2 against HR-EFH

FIGURE 12: Absolute difference in the TIS levels owing to hand-hold alteration at different antenna/handset positions against HR-EFH in GSM900, GSM1800, and UMTS/IMT-2000 bands.

\subsection{Comparison between SAM and HE-EFH simulation effects}

Many researchers have investigated the SAR in both SAMand MRI-based human head due to the handset antennas exposure. Study by some researchers concluded that SAM underestimates SAR in adult MRI-based head, whereas, some other researchers concluded that SAM overestimates SAR in MRI-based adult head. Simultaneously, some researchers have presented mixed results. Light has been shed in detail on all these three states in [34] indicating the potential causes of discrepancies.
The simulations carried out in this work bring to light SAR difference in SAM and HR-EFH as explained here. According to the adopted handset positions with respect to head, inclusion of the pinna in the 1 and $10 \mathrm{~g}$ SAR averaging volumes for the HR-EFH and the database used to define the tissues parameters, the SAM has always been found underestimating SAR in HR-EFH by a factor ranging from 1.0 to 2.0 , with the exception of the handset models being at cheek positions and operating at $900 \mathrm{MHz}$, where SAM overestimates SAR in HR-EFH by a factor ranging from 1.0 to 1.4. The SAR results and its behavior in both SAM and HREFH owing to handsets exposure at different setups coincide 


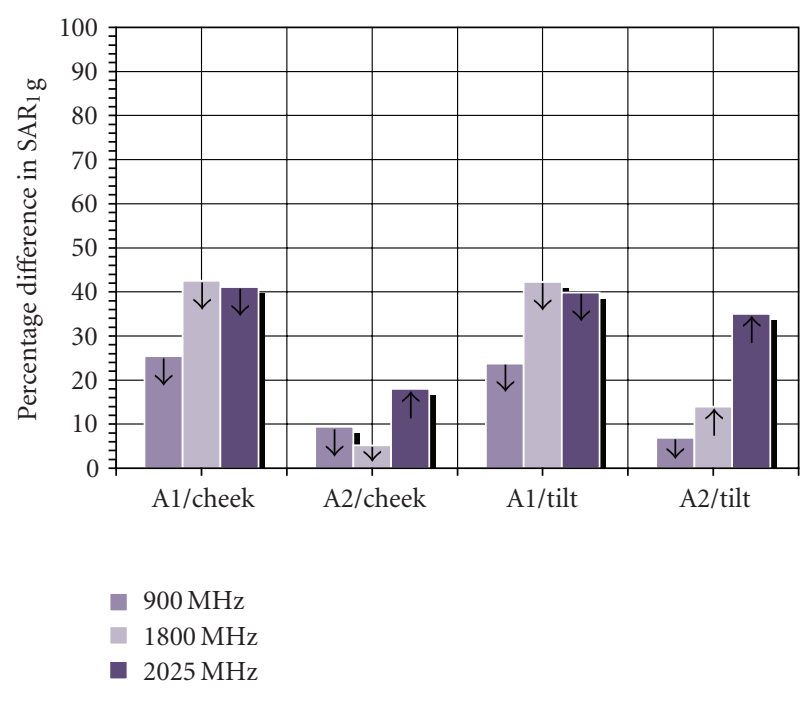

(a) Models-A1 and A2 against HR-EFH

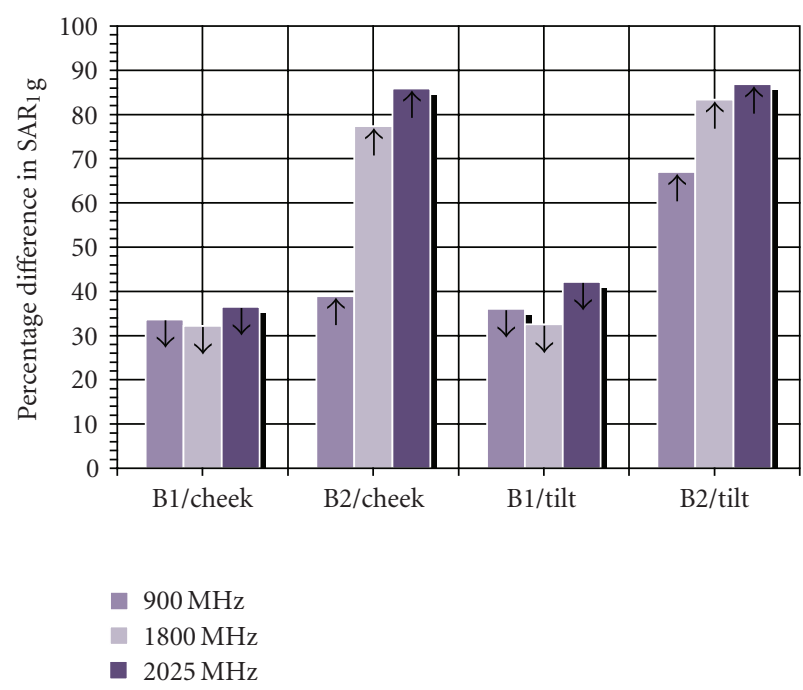

(b) Models-B1 and B2 against HR-EFH

FIgURE 13: Percentage difference in the averaged-peak $S_{1 \mathrm{R}}$ values in HR-EFH, owing to hand-hold alteration, at different antenna/handset positions in GSM900, GSM1800, and UMTS/IMT2000 bands.

with those presented by the (IEEE SCC-34/SC-2/WG-2) [34] while considering all tissue including the pinna for the MRIbased adult head.

SAM and HR-EFH get different SAR values and absorb different amount of powers because of the differences between their volumes, masses, and homogeneities. The volume and mass of the SAM phantom are approximately $5825 \mathrm{~cm}^{3}$ and $6.018 \mathrm{~kg}$ (considering a homogeneous density of $1030 \mathrm{~kg} / \mathrm{m}^{3}$ ), respectively, whereas, volume and mass of the HR-EFH model are approximately $4063 \mathrm{~cm}^{3}$ and $4.7158 \mathrm{~kg}$, respectively. The accuracy of volume and mass calculation depends on the FDTD-grid spatial resolution and number of cells.
Figures 5 and 6 expose an inconsiderable difference in the antenna far-field radiation pattern because of the presence of heterogeneous head tissues (HR-EFH), as compared to the homogeneous tissues (SAM).

\subsection{Power budget error}

For the same FDTD-grid setting, handset in hand close to HR-EFH needs more number of grid cells to be simulated, as compared with handset close to SAM. It is true even with duplicating the refining factor of SAM solid regions (shell and liquid). It is because of homogeneous property of the SAM phantom in which the spatial resolution along the head tissue gradually increases from the minimum to maximum in short distance at each axis. As concerning the heterogeneous HR-EFH model, the minimum spatial resolution has no big chances to reach the maximum value at each axis owing to the existence of the twenty five different tissues. Consequently, for the same FDTD-grid setting, the power budget error in cases with the HR-EFH is less than in cases with the SAM. As revealed in Tables $8-10$, the power budget errors in simulations are around $2 \%$.

\subsection{Computational requirements}

All computations were performed on a $2 \mathrm{GHz}$ Intel centrino Laptop machine (Dell, inspiron-630 m) with 2 GB memory and a $1.6 \mathrm{GHz}$ dual core Intel Pentium machine (Acer, Aspire M1600) with 4 GB memory.

The runtime and memory requirements depend on the simulation space as well as the refinement factor for each solid region. Less memory and runtime were required for the handset simulation in free space, whereas more memory and runtime were required for the handset in hand close to head. The maximum number of FDTD-grid cells that can be achieved with the adopted simulating machines is about 24 Mcells, where a hardware accelerator aXware [27] is not used. The machine memories were enough to achieve all simulations where the runtimes were about 1-10 hours depending on the total number of grid cells.

\section{CONCLUSIOIN}

On the bases of the handset, hand, and head models used in this research, it has been significantly elaborated that the hand-hold position has a considerable impact on the EM interaction between cellular handset and human. Other related factors such as the operating frequency, antenna type/position, and the handset position against head were assessed while anticipating the hand impact. To achieve realistic in-use conditions, different candy-bar handset models having external and internal antennas operating in GSM900, GSM1800, and UMTS/IMT-2000 bands were simulated, whereas semirealistic hand model of three tissues, MRIbased adult female head model of twenty five tissues, and SAM phantom were selected for evaluating the EM interaction. Owing to the hand-hold alteration, more differences in values of the antenna total efficiency, total isotropic sensitivity, and both SAR and power absorption in tissues 


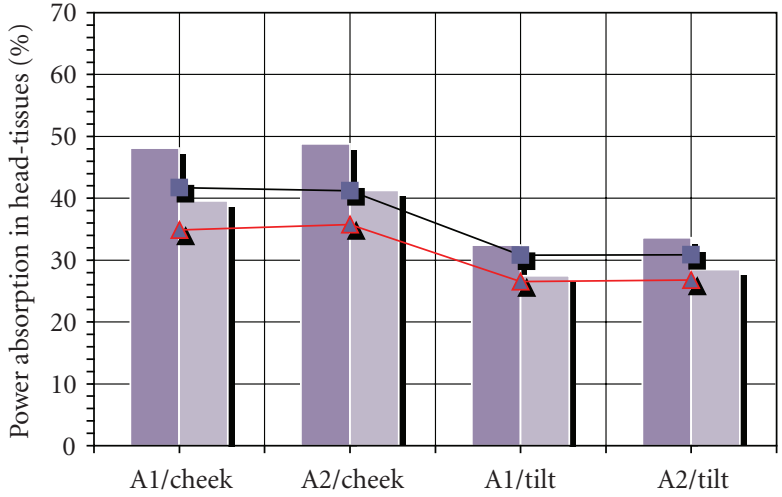

(a) Models-A1 and A2 at $900 \mathrm{MHz}$

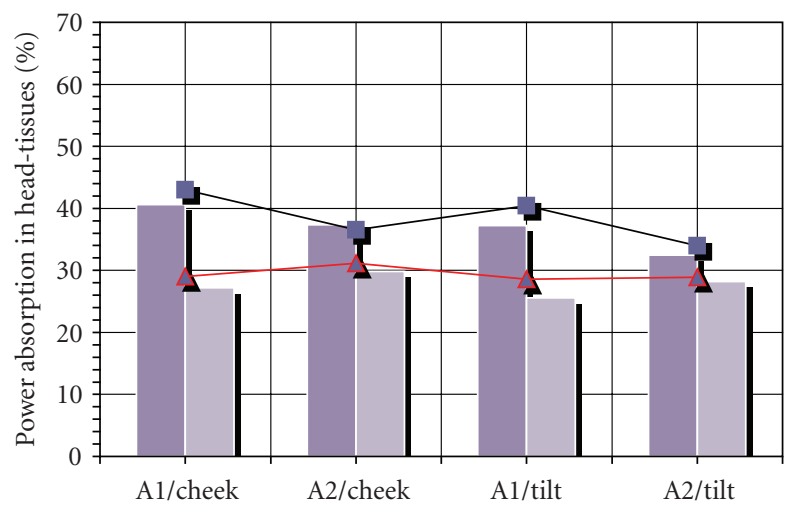

(c) Models-A1 and A2 at $1800 \mathrm{MHz}$
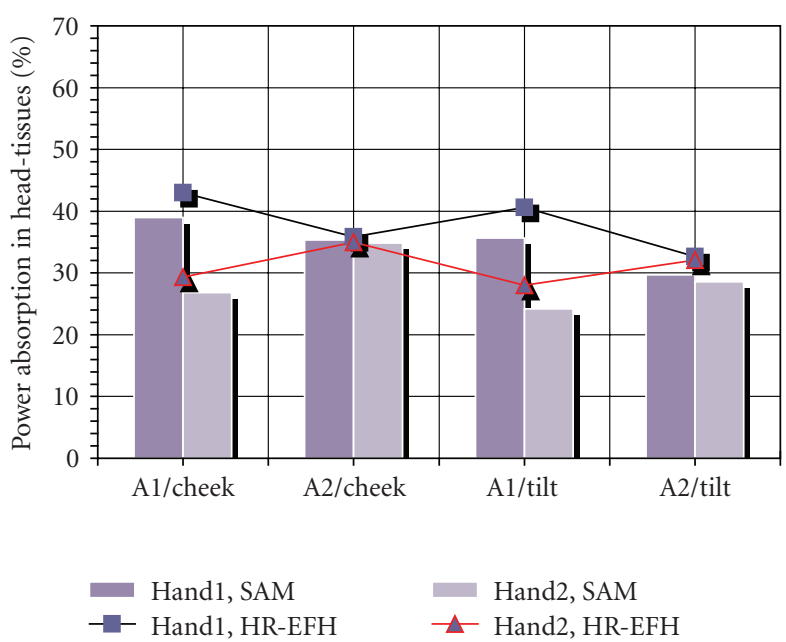

(e) Models-A1 and A2 at $2025 \mathrm{MHz}$

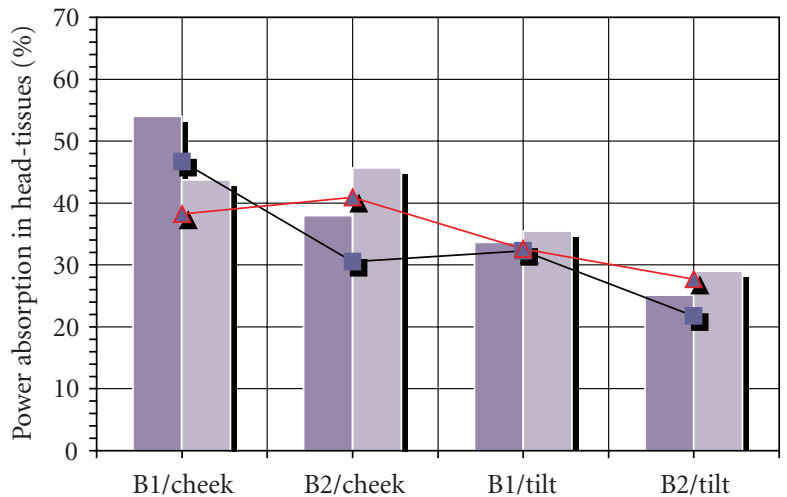

(b) Models-B1 and B2 at $900 \mathrm{MHz}$

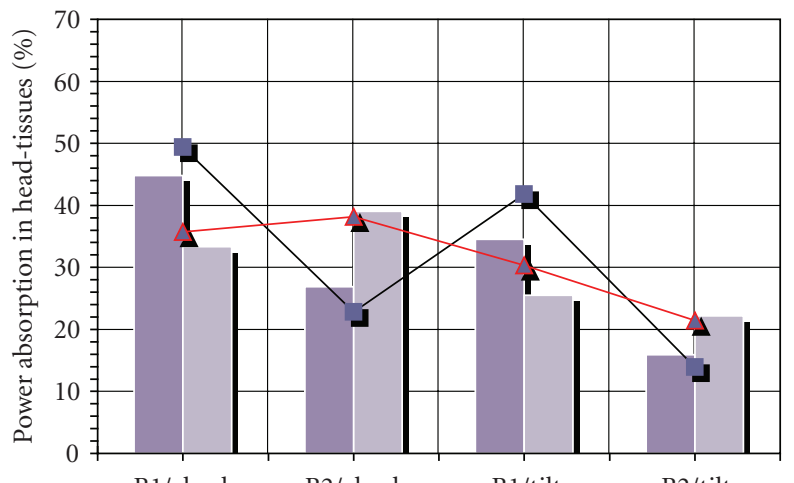

(d) Models-B1 and B2 at $1800 \mathrm{MHz}$

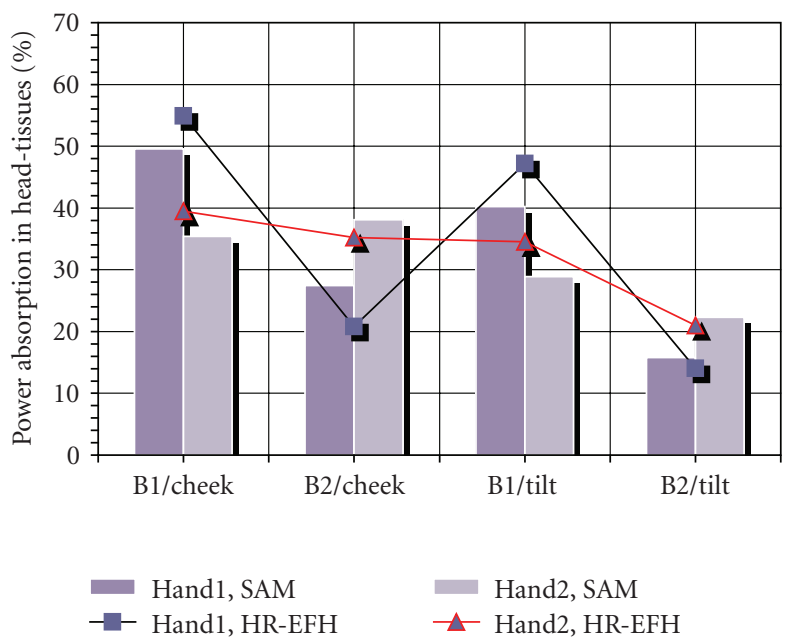

(f) Models-B1 and B2 at $2025 \mathrm{MHz}$

FIGURE 14: Percentage power absorption in head tissues at different antenna/handset positions in GSM900, GSM1800, and UMTS/IMT2000 bands.

were recorded with the handset models having internal patch antenna, as compared with the handset models having external loaded short-whip antenna. This paper showed interesting results; in a certain usage pattern of a handset having left-side external antenna, the maximum percentage difference of spatial-peak $\mathrm{SAR}_{1 \mathrm{~g}}$ values in head due to the right hand-hold alteration may reach over $42 \%$, whereas it may reach over $86 \%$ with the handset having bottommounted internal patch antenna. The power budget errors in the proposed simulations were around $2 \%$. 


\section{ACKNOWLEDGMENTS}

The authors would like to thank reverent Wayne Jennings, Application Engineer, SPEAG Schmid \& Partner Engineering AG for the kind assistance in providing the numerical corrected model of a human head (HR-EFH). They would like to express their gratitude to Professor M. L. Chaudhary, the Higher Institute of Electronics for his kind assistance in removing the linguistic errors in this article.

\section{REFERENCES}

[1] IEEE Standard-1528, "IEEE Recommended Practice for Determining the Peak Spatial-Average Specific Absorption Rate (SAR) in the Human Head from Wireless Communications Devices: Measurement Techniques," December 2003.

[2] "Product standard to demonstrate the compliance of mobile phones with the basic restrictions related to human exposure to electromagnetic fields ( $300 \mathrm{MHz}-3 \mathrm{GHz}$ ), European Committee for Electrical Standardization (CENELEC), EN 50360, Brussels, 2001.

[3] "Basic Standard for the Measurement of Specific Absorption Rate Related to Exposure to Electromagnetic Fields from Mobile Phones (300 MHz-3 GHz)," European Committee for Electrical Standardization (CENELEC), EN-50361, 2001.

[4] "Procedure to measure the Specific Absorption Rate (SAR) in the frequency range of $300 \mathrm{MHz}$ to $3 \mathrm{GHz}$ - part 1: handheld mobile wireless communication devices," International Electrotechnical Commission, committee draft for vote, IEC 62209.

[5] "Specific Absorption Rate (SAR) Estimation for Cellular Phone," Association of Radio Industries and businesses, ARIB STD-T56, 2002.

[6] "Evaluating Compliance with FCC Guidelines for Human Exposure to Radio Frequency Electromagnetic Field, Supplement C to OET Bulletin 65 (Edition 9701)," Federal Communications Commission (FCC), Washington, DC, USA, 1997.

[7] ACA Radio communications (Electromagnetic RadiationHuman Exposure) Standard 2003, Schedules 1 and 2, Australian Communications Authority.

[8] J. Toftgard, S. N. Hornsleth, and J. B. Andersen, "Effects on portable antennas of the presence of a person," IEEE Transactions on Antennas and Propagation, vol. 41, no. 6, pp. 739-746, 1993.

[9] M. A. Jensen and Y. Rahmat-Samii, "EM interaction of handset antennas and a human in personal communications," Proceedings of the IEEE, vol. 83, no. 1, pp. 7-17, 1995.

[10] M. Okoniewski and M. A. Stuchly, "A study of the handset antenna and human body interaction," IEEE Transactions on Microwave Theory and Techniques, vol. 44, no. 10, part 2, pp. 1855-1864, 1996.

[11] J. T. Rowley and R. B. Waterhouse, "Performance of shorted microstrip patch antennas for mobile communications handsets at $1800 \mathrm{MHz}$," IEEE Transactions on Antennas and Propagation, vol. 47, no. 5, pp. 815-822, 1999.

[12] O. Kivekäs, J. Ollikainen, T. Lehtiniemi, and P. Vainikainen, "Bandwidth, SAR, and efficiency of internal mobile phone antennas," IEEE Transactions on Electromagnetic Compatibility, vol. 46, no. 1, pp. 71-86, 2004.

[13] S.-I. Watanabe, H. Taki, T. Nojima, and O. Fujiwara, "Characteristics of the SAR distributions in a head exposed to electromagnetic fields radiated by a hand-held portable radio,"
IEEE Transactions on Microwave Theory and Techniques, vol. 44, no. 10, part 2, pp. 1874-1883, 1996.

[14] J. Graffin, N. Rots, and G. F. Pedersen, "Radiations phantom for handheld phones," in Proceedings of the IEEE Vehicular Technology Conference (VTC '00), vol. 2, pp. 853-860, Boston, Mass, USA, September 2000.

[15] M. Francavilla, A. Schiavoni, P. Bertotto, and G. Richiardi, "Effect of the hand on cellular phone radiation," IEE Proceedings: Microwaves, Antennas and Propagation, vol. 148, no. 4, pp. 247-253, 2001.

[16] N. Chavannes, P. Futter, R. Tay, K. Pokovic, and N. Kuster, "Reliable prediction of mobile phone performance for different daily usage patterns using the FDTD method," in Proceedings of the IEEE International Workshop on Antenna Technology (IWAT '06), pp. 345-348, White Plains, NY, USA, March 2006.

[17] C.-M. Su, C.-H. Wu, K.-L. Wong, S.-H. Yeh, and C.-L. Tang, "User's hand effects on EMC internal GSM/DCS mobile phone antenna," in Proceedings of the IEEE Antennas and Propagation Society International Symposium (APS '06), pp. 2097-2100, Albuquerque, NM, USA, July 2006.

[18] J. A. Vaul and P. S. Excell, "Numerical realisation of realistic articulated hand model for mobile telephone dosimetry studies," in Proceedings of the 22nd Annual Meeting of the Bioelectromagnetic Society, p. 141, Munich, Germany, June 2000.

[19] M. Lundmark, R. S. Calvo, P.-S. Kildal, and C. Orlenius, "A solid hand phantom for mobile phones and results of measurements in reverberation chamber," in Proceedings of the IEEE Antennas and Propagation Society International Symposium, vol. 1, pp. 719-722, Monterey, Calif, USA, June 2004.

[20] S. I. Al-Mously and M. M. Abousetta, "Study of both antenna and PCB positions effect on the coupling between the cellular hand-set and human head at GSM-900 standard," in Proceedings of the International Workshop on Antenna Technology (iWAT '08), vol. , pp. 513-517, Chiba, Japan, March 2008.

[21] S. I. Al-Mously and M. M. Abousetta, "A novel cellular handset design for an enhanced antenna performance and a reduced SAR in the human head," International Journal of Antennas and Propagation, vol. 2008, Article ID 642572, 10 pages, 2008.

[22] S. I. Al-Mously and M. M. Abousetta, "A study of the handhold impact on the EM interaction of a cellular handset and a human head," International Journal of Electronics, Circuits, and Systems, vol. 2, no. 2, pp. 91-95, 2008.

[23] P. Futter, N. Chavannes, R. Tay, et al., "Reliable prediction of mobile phone performance for realistic in-use conditions using the FDTD method," IEEE Antennas and Propagation Magazine, vol. 50, no. 1, pp. 87-96, 2008.

[24] K. S. Yee, "Numerical solution of inital boundary value problems involving Maxwell's equations in isotropic media ," IEEE Transaction on Antennas and Propagation, vol. 14, no. 3, pp. 302-307, 1966.

[25] F. Gustrau and D. Manteuffel, EM Modeling of Antennas and RF Components for Wireless Communication Systems, Springer, Munich, Germany, 2006.

[26] N. Chavannes, R. Tay, N. Nikoloski, and N. Kuster, "Suitability of FDTD-based TCAD tools RF design of mobile phones," IEEE Antennas and Propagation Magazine, vol. 45, no. 6, pp. 52-66, 2003.

[27] SEMCAD X, "Reference Manual for the SEMCAD Simulation Platform for Electromagnetic Compatibility, Antenna Design 
and Dosimetry," SPEAG - Schmid \& Partner Engineering AG, http://www.semcad.com/.

[28] K. Ogawa and T. Uwano, "A diversity antenna for very small $800-\mathrm{MHz}$ band portable telephones," IEEE Transactions on Antennas and Propagation, vol. 42, no. 9, pp. 1342-1345, 1994.

[29] K. Hiraswa and M. Haneishi, Analysis, Design, and Measurement of Small and Low-Profile Antennas, Artech House, London, UK, 1992.

[30] K.-L. Wong, Compact and Broadband Microstrip Antennas, John Wiley \& Sons, New York, NY, USA, 2002.

[31] M. Burkhardt, Contributions toward uncertainty assessments and error minimization of FDTD simulations involving complex dielectric bodies, Ph.D. thesis, ETH, Zurich, Switzerland, 1999, Nr.13176.

[32] "Dielectric Properties of Body Tissue in the frequency range $10 \mathrm{~Hz}-100 \mathrm{GHz}$," Italian National Research Council, Institute for Applied Physics, Florence, Italy, http://niremf.ifac .cnr.it/tissprop.

[33] C. Gabriel, "Compilation of the dielectric properties of body tissues at RF and microwave frequencies," Tech. Rep. N.AL/OE-TR-1996-0037, Occupational and Environmental Health Directorate, Radiofrequency Radiation Division, Brooks Air Force Base, San Antonio, Tex, USA, June 1996.

[34] B. B. Beard, W. Kainz, T. Onishi, et al., "Comparisons of computed mobile phone induced SAR in the SAM phantom to that in anatomically correct models of the human head," IEEE Transactions on Electromagnetic Compatibility, vol. 48, no. 2, pp. 397-407, 2006.

[35] Z. N. Chen, Antennas for Portable Devices, John Wiley \& Sons, New York, NY, USA, 2007.

[36] P. Lindberg, Wideband active and passive antenna solutions for handheld terminals, Ph.D. thesis, Faculty of Science and Technology 266, Uppsala University, Uppsala, Sweden, 2007.

[37] C. Orlenius, P.-S. Kildal, and G. Poilasne, "Measurements of total isotropic sensitivity and average fading sensitivity of CDMA phones in reverberation chamber," in Proceedings of the IEEE Antennas and Propagation Society International Symposium, vol. 1A, pp. 409-412, Washington, DC, USA, July 2005.

[38] C. Orlenius, N. Serafimov, and P.-S. Kildal, "Procedure for measuring radiation efficiency in downlink band for active mobile phones in a reverberation chamber," in Proceedings of the IEEE Antennas and Propagation Society International Symposium, vol. 4, pp. 731-734, Columbus, Ohio, USA, June 2003.

[39] H. Arai, Measurement of Mobile Antenna Systems, Artech House, London, UK, 2001.

[40] IEEE-1529, draft standard, "Recommended Practice for Determining the Peak Spatial-Average Specific Absorption Rate (SAR) associated with the use of wireless handsets-computational techniques".

[41] IEEE Standard C95.1b-2004, "IEEE Standard for Safety Levels with respect to human exposure to radio frequency electromagnetic fields, $3 \mathrm{kHz}$ to $300 \mathrm{GHz}$, Amendment 2: Specific Absorption Rate (SAR) Limits for the Pinna," December 2004.

[42] L. C. Kuo, Y. C. Kan, and H. R. Chuang, "Analysis of a 900/1800-MHZ dual-band gap loop antenna on a handset with proximate head and hand model," Journal of Electromagnetic Waves and Applications, vol. 21, no. 1, pp. 107-122, 2007. 

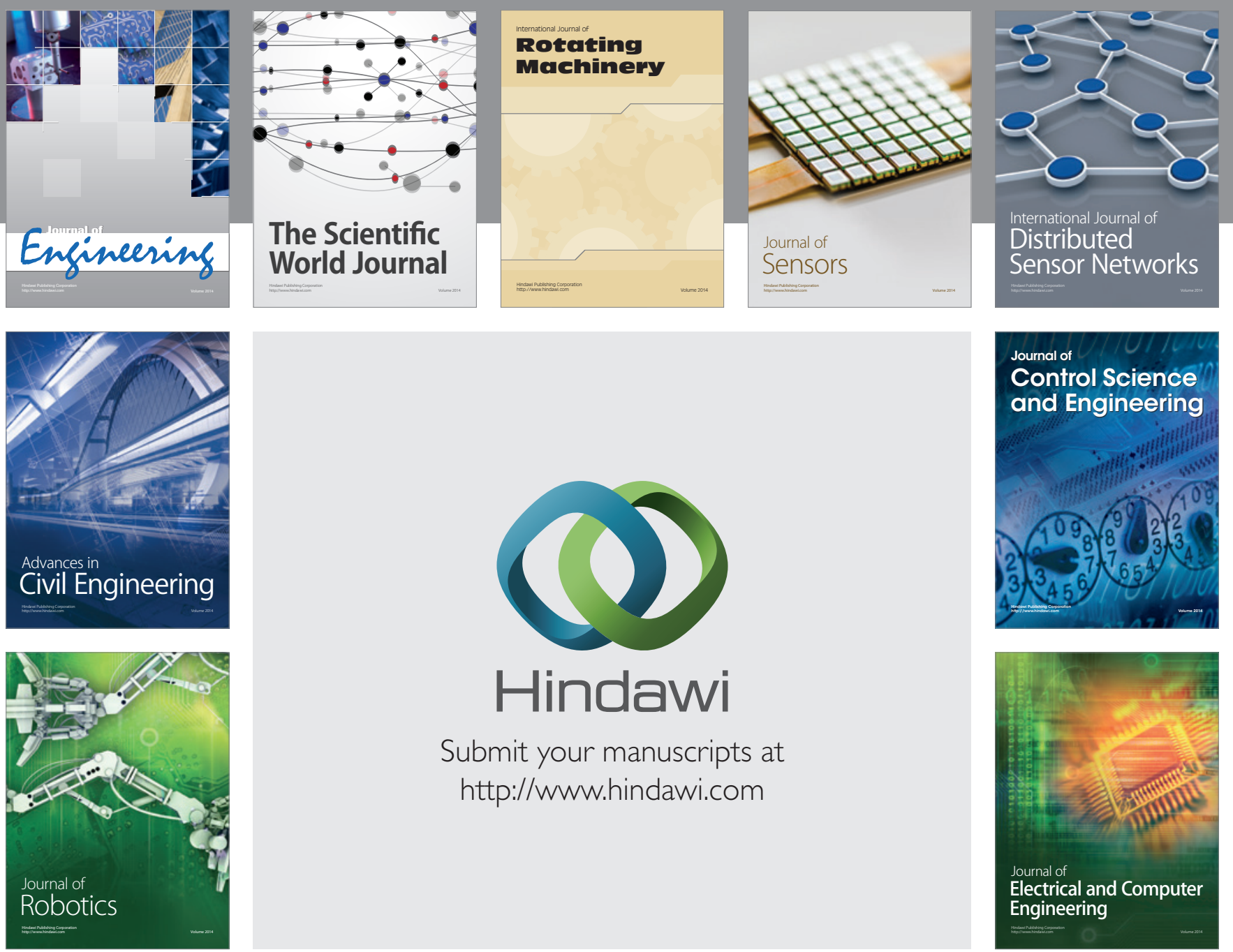

Submit your manuscripts at

http://www.hindawi.com
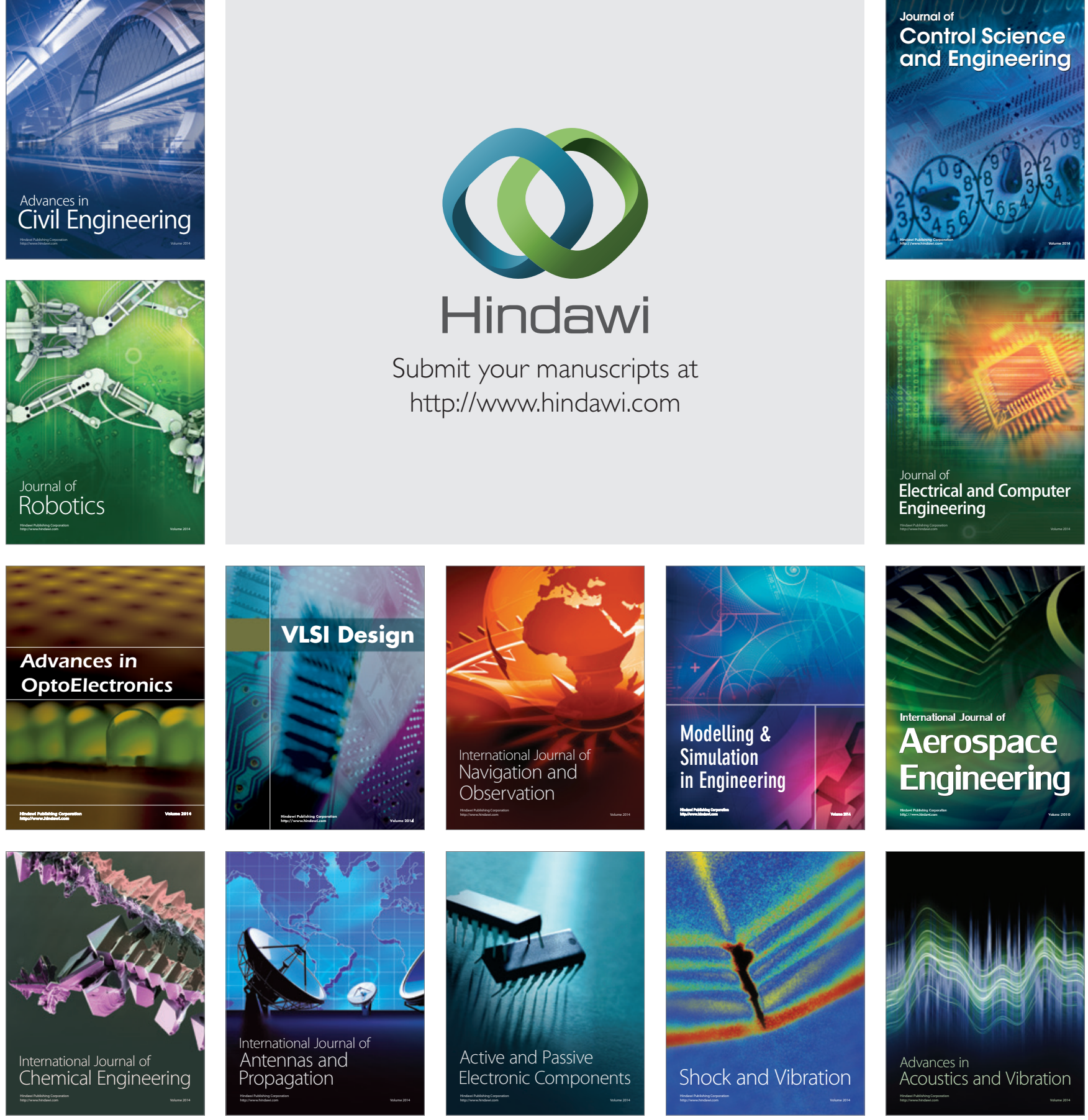